$\mathcal{G S}_{\text {http://dx.doi.org/10.3765/sp.9.5 }}^{\text {Semantics \& Pragmatics Volume 9, Article 5: 1-61, } 2016}$

\title{
Supplemental update*
}

\author{
Scott Martin \\ Nuance Communications
}

Submitted 2015-02-03 / First decision 2015-05-12 / Revision received 2015-06-04 /

Accepted 2015-10-07 / Early access published 2016-04-28 / Published 2017-03-12

\begin{abstract}
Supplements have often been characterized as inert with respect to other content. But under closer scrutiny, the data shows that supplements can take scope and participate in anaphoric links, undermining multidimensional accounts of them. I argue that the core empirical facts pertaining to supplements, including projection, can in many cases be accounted for by more general, independently motivated factors such as anaphora resolution in discourse and quantifier scope preferences. Importantly, supplement projection is decoupled from at-issueness, with projection arising instead as an epiphenomenon of various external influences.

The account is formalized in a dynamic, compositional, and unidimensional semantics that allows anaphoric links to and from supplement content. Since supplements are modeled as a kind of quantifier phrase modifier, scope interactions with semantic operators are captured without further stipulation. When a supplement takes widest scope, it constitutes a separate at-issue proposal, enabling both supplement projection and (non)deniability. The formal machinery requires no additional rules or representation layers except for the dynamic meaning of the comma intonation, which demarcates a supplement from its surrounding content.
\end{abstract}

Keywords: dynamic semantics, projection, scope, supplements, unidimensional semantics

* For helpful comments and criticism on earlier drafts, I am grateful to Lelia Glass, Greg Kierstead, Todor Koev, Carl Pollard, Chris Potts, and Craige Roberts, audiences at Semantics and Linguistic Theory 2012 and at Stanford University, as well as to the Semantics and Pragmatics editors and anonymous reviewers. I am also especially grateful to Yusuke Kubota, whose suggestions greatly improved both the presentation and the formal analysis.

(C)2016 Scott Martin

This is an open-access article distributed under the terms of a Creative Commons Attribution License (https://creativecommons.org/licenses/by/3.o/). 
Scott Martin

\section{Introduction}

Potts (2005) revitalized interest in supplements, the class of constructions that includes nominal appositives, nonrestrictive relative clauses, and asparentheticals, arguing that they are inert with respect to semantic operators - scopeless, in his terms - as a result of not being at-issue. Inspired partly by earlier work on modeling conventional implicature by Karttunen \& Peters (1979), Potts invokes these arguments to motivate an account that detaches the semantic contribution of a supplement into a separate meaning dimension that is entirely divorced from the rest of the surrounding utterance's content.

However, there is a mounting body of evidence that a multidimensional semantics is inappropriate for modeling supplements because of their ability to interact compositionally with surrounding content. Several authors (Amaral, Roberts \& Smith 2007, AnderBois, Brasoveanu \& Henderson 2010, 2015, Koev 2012, 2014, Martin 2013) point out that a supplement can both contain elements that are anaphoric to an antecedent occurring outside it, as well as introduce antecedents for subsequent anaphora. Others (del Gobbo 2007; Nouwen 2007, 2014; Schlenker 2010, 2013a, 2013b) draw attention to the fact, already noticed by Amaral, Roberts \& Smith, that supplements are sometimes interpreted in the scope of operators. Based on the fact that they may be directly denied, AnderBois, Brasoveanu \& Henderson, Koev, and Schlenker even call into question the notion that supplements are never at-issue. But a unidimensional approach to supplements, as Nouwen (2014) notes, also immediately encounters the challenge of explaining how supplement content projects past semantic operators, in Tonhauser et al.'s (2013) terminology, escaping their effects.

In this paper, I propose a novel account of supplements in a unidimensional dynamic semantics that synthesizes elements of previous approaches, giving supplements both an incremental interpretation and the capacity to take scope. The central idea is that the comma intonation associated with supplements (Huddleston \& Pullum 2002: 1351) triggers a kind of quantifier phrase (QP) modification, illustrated informally by the following example:
$\overbrace{\text { cyclist }}^{Q} \overbrace{\text { a doper }}^{D}$
E
a. Some cyclist,$\overbrace{\text { a doper }}$, $\overbrace{\text { won the Tour de France. }}$
b. $(Q D)$ AND (THE $D E$ )

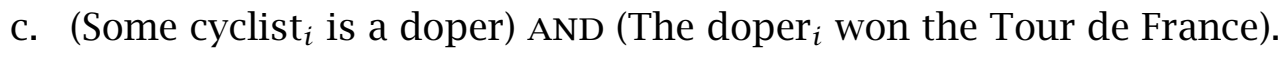


Supplemental update

As (1a) shows, an utterance containing a supplement consists of a QP $Q$ (here, Some cyclist) and two properties: $D$, the apposition $a$ doper, a predicativized generalized quantifier (GQ), and the scope E (won the Tour de France). A rough approximation of the comma intonation's semantics is in (1b): the utterance's contribution is broken into two parts, the first $(Q D)$ applying the quantificational force of the determiner to the apposition, the second (THE $D E$ ) anaphorically selecting the most salient discourse referent with the apposition property $D$ and passing it to the scope $E$. As usual in dynamic theories, the conjunction AND is asymmetric, so that the first conjunct's content is processed before the second's, in the sense that the second has access to the updates made by the first, but not vice versa. Finally, (1c) shows informally how this semantics is instantiated for (1a), with dynamic conjunction separating the information that some cyclist is a doper from the information that the doper won the Tour de France.

An immediate consequence of this approach is to enable scope interactions for supplements, because they are treated semantically as piggybacking onto their GQ anchors. Unembedded dynamic conjunction is semantically equivalent to parataxis in this model, as shown in Theorem A.2. As a result, a supplement in widest scope position, as in (1), contributes a separate proposal from the main clause content - a supplemental update - when it is proffered. By contrast, a narrow-scoping supplement is interpreted as simply being dynamically conjoined with the main clause content. When no embedding operators are present, a supplement can only take widest scope, and so supplements in root clauses containing no operators always project.

Supplements thus contribute ordinary at-issue denotations, and their apparent projection derives from independent mechanisms, such as the properties of the anchoring GQ. In this respect, this account breaks with many others because it decouples supplement projection from at-issueness: a supplement may project independently of whether or not it addresses the question under discussion (QUD, Simons et al. 2010, Ginzburg 2012, Roberts 2012a,b). Whether a supplement projects is, as a result, just an epiphenomenon of its anchor's scope. In some cases, it derives from the tendency to take widest scope exhibited by proper names and other definites. In others, it follows from the preference for surface scope independently observed for GQs. The fact that supplements are sometimes forced to take narrow scope is based on the more general notion of anaphoric accessibility in discourse, following Nouwen (2014). And since the sequence of proposals generated by an utterance containing a supplement is ordered by linear position, this account 
gives a model of the greater degree of deniability observed for utterance-final supplements (AnderBois, Brasoveanu \& Henderson 2010, 2015, Koev 2012, Schlenker 2013b). I also offer new examples that show a supplement in the scope of a quantifier being interpreted outside its scope, and argue that these cases are instances of Roberts's (1989) telescoping.

The semantics itself is both dynamic and fully compositional, in the tradition of Muskens (1994, 1996), Beaver (2001), de Groote (2006), Martin \& Pollard (2012a,b, 2014), and Martin (2013). Apart from the specialized meaning for the comma intonation, this semantics only uses independently motivated mechanisms to model supplements: incremental discourse composition, anaphora resolution, predicativization, and generalized quantification. Only a single meaning dimension is required, with no additional special-purpose rules or representation layers, and the account is expressed in the well understood, mainstream mathematical formalism of type theory familiar to many semanticists.

The following section (Section 2) discusses the empirical domain of supplements, focusing in particular on their projection and scope-taking capabilities (Section 2.1). In Section 2.1.3, I present new data showing that quantified supplements can sometimes be interpreted outside the scope of their anchors. The gradience of supplement deniability is discussed in Section 2.2. A formal account of supplements is given in Section 3, with Section 3.1 briefly touching on some preliminaries that are detailed more fully in the appendix. After giving some basic ingredients in Section 3.2, such as the process of making an at-issue proposal (Section 3.2.1) and the comma intonation (Section 3.2.2), I formally analyze supplements interacting with anaphora (Section 3.3), supplement scope and projection (Section 3.4), including cases of quantified supplements (Section 3.4.3) and supplement deniability (Section 3.4.4). A summary and comparison with previous accounts is given in Section 4; conclusions and future work are discussed in Section 5.

\section{Characterizing supplements}

A paradigm example of a supplement in a root clause with no embedding operators is given in

(2) Ames, a successful spy, is now behind bars.

(Potts 2005: 90, (4.2); emphasis mine) 
Supplemental update

In supplement constructions like this one, the apposition a successful spy, is attached to its anchor Ames (Huddleston \& Pullum 2002: 1351) via the comma intonation, the distinct pattern of intonational pauses that demarcates supplements in spoken English, often represented in writing by a pair of commas.

Cases like (2) prompt the observation that the supplements in them are interpreted separately from the surrounding content. For example, in the variant in (3), the implication that Ames is a successful spy is not perturbed by the negation targeting the matrix verb.

(3) It's not true that Ames, a successful spy, is currently behind bars.

The meaning of (3) could equivalently be captured by either of the following:

(4) a. Ames $i$ is a successful spy, and he ${ }_{i}$ is not currently behind bars.

b. Ames ${ }_{i}$ is a successful spy. $\mathrm{He}_{i}$ is not currently behind bars.

Both of the alternatives in (4) contain two separate proposals, the first of which contains the content expressed by the supplement in (3), and the second the content expressed by its main clause. Based on this behavior, Potts and many others have claimed that supplement content cannot be targeted by semantic operators, and that it obligatorily projects (Simons et al. 2010, Tonhauser et al. 2013).

The interpretations in (4) are part of a general pattern, as the syntactic distribution of appositions shows a high degree of overlap with predicatives:

(5) Kim, (who’s)

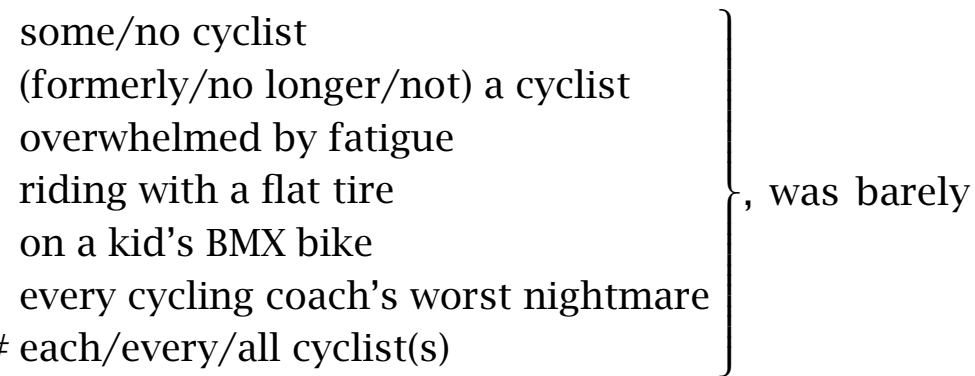
able to make it up Old La Honda Road in half an hour.

The capability of each of the appositions bracketed in (5) to occur as the complement to the copula follows the same pattern, ${ }^{1}$ and so do the relevant adaptations of those in

1 Although Chaka Khan, Whitney Houston, and Taylor Swift did all sing I'm every woman, I take this to be a metaphorical usage. 
(6) Lance, $\left\{\begin{array}{l}\text { his rear brake dragging } \\ \text { with an injured leg } \\ \text { having missed the big move }\end{array}\right\}$, dropped out of the race.

That is, the copular expression Lance's leg was injured is possible.

\subsection{Supplement scope and projection}

The interpretations in (4) are not the only ones available for (3), since the wide-scope negation reading could perhaps be forced by following up (3) with The Ames you're thinking of, the one that went to jail, is actually a hedge fund manager. Nouwen (2014) points out other cases where a negation-wide reading seems possible:

(7) It is not the case that a boxer, a famous one, lives in this street.

(Nouwen 2014: (25))

This example can be interpreted equivalently with No famous boxer lives in this street, although a reading with the supplement projecting is also available. Importantly, in the negation-wide readings of both (3) and (7), the supplement does not constitute a separate proposal, instead becoming integrated into the negated content.

As evidence that supplements can be outscoped by operators other than negation, consider the following:

(8) Every professional man I polled ${\text { said that while his }{ }_{i} \text { wife }_{j} \text {, who }}_{j}$ had earned a bachelor's degree, nevertheless had no work experience, he ${ }_{i}$ thought she ${ }_{j}$ could use it to get a good job if she ${ }_{j}$ needed one.

(Amaral, Roberts \& Smith 2007: 740, (35); indices mine)

In this example, the supplement must be interpreted in the scope of Every because its anchor is interpreted there: (8) entails that each professional man polled claimed his wife had earned a degree. The same effect is observed when the supplement's anchor uses the indefinite determiner:

(9) Every professor who wrote a book, one on linguistics, is eligible for a sabbatical.

(10) Every boxer has a coach, a famous one.

(Nouwen 2014: (24) and (32))

The natural interpretation for (9) has each professor writing a different book on linguistics, and for (10), the reading where there is a potentially different 
Supplemental update

famous coach for each boxer is available (though a wide-scope or specific indefinite reading is also possible). Amaral, Roberts \& Smith (2007: 741, (38)) also show that iterative adverbs like too that occur in supplements can be licensed by information in the scope of a quantifier.

The interaction between supplements and scope-taking operators is not restricted to negation and quantification. Schlenker (2013b) argues at length that they can sometimes take narrow scope within conditionals, as in the following.

(11) Context: Someone made a big mistake at the department.

(12) a. If tomorrow I call the chair, who in turn calls the dean, then we will be in deep trouble. (Schlenker 2013b: 7, (11))

b. If tomorrow I call the chair, a total jerk, then we will be in deep trouble.

For (12b), the implication that the chair is a total jerk is independent of whether I call her or not, that is, the supplement projects. By contrast, in (12a), the supplement is obligatorily interpreted in the antecedent of the conditional: there is no implication that the chair will necessarily call the dean no matter what, just that if I call the chair, s/he will call the dean as a result.

Nouwen (2014) summarizes the scope dependency between an apposition and its anchor by observing that "[t]he scope of the appositive is always at least as wide as that of its anchor, never narrower." Based on the data discussed here, I propose that a supplement is formed by an apposition that attaches itself to an anchoring GQ, augmenting its content and taking the exact same scope as the anchor, with the "at least as wide" part of Nouwen's observation falling out as a result. When a supplement's anchor scopes widest, as in the reading of (3) with negation narrow, a separate proposal is generated for the supplement content, and so it projects past any operators in the main clause. But when its anchor takes narrow scope, as in (8), the supplement does not project, its content instead becoming integrated into the main clause content.

With supplements allowed to take scope along with their anchors, how do the readings with the supplement obligatorily in widest scope position - that is, the projective readings - arise? And what factors act to prevent these readings? I turn to these questions in the following sections. 
Scott Martin

\subsubsection{Discourse anaphora}

Nouwen (2014: note 3) also seems to be the first to notice "the parallel $[\ldots]$ between discourse anaphora with quantifiers and the anchoring of an appositive", one of the factors influencing supplement projection:

(13) a. Every cyclist ${ }_{i}$ met a friend of hers $s_{i}$ for a beer.

b. Every cyclist $t_{i}$ met Lance, who gave $\operatorname{him}_{i}$ a Tour de France souvenir.

c. Every cyclist met Lance, a doper who cheated to win the Tour de France.

On the intended reading, (13a) means that for each cyclist, that cyclist met a potentially different friend of hers for a beer. It cannot mean that there was necessarily a single friend that met all of the cyclists for a beer, that is, the indefinite cannot take widest scope due to the presence of the bound pronoun hers. This seems to be the same reason why the supplement in (13b) cannot be construed projectively, that is, as taking widest scope, whereas in (13c) it clearly can: (13b) means that Lance gave each of the cyclists a different Tour souvenir, while (13c) has an interpretation equivalent to Lance, who by the way is a doper and cheated in the Tour, was met by every cyclist. Thus the presence of the bound pronoun in (13b) acts to block the projective reading that would normally arise. ${ }^{2}$

Given this observation, (12a) bears a similarity to (14), interpreted in the same context (11):

(14) If tomorrow [I call the chair $\left.]_{j}\right]_{j}$, which ${ }_{j} \operatorname{prompts~her~}_{i}$ to call the dean, then we will be in deep trouble.

The important modification in (14) is to make the event anaphora more obvious. In this adaptation, the phrase I call the chair introduces a discourse referent corresponding to the calling event, which is interpreted in the scope of tomorrow. In (12a), by comparison, the event anaphora is instead signaled

2 A reviewer reminded me of the existence of examples where a pronoun in a supplement appears to be bound within the scope of an operator, but the supplement is interpreted outside. I discuss examples of exceptional scope, such as (27), below in Section 2.1.3, and argue that they are instances of telescoping, different from cases of discourse binding such as $(13 b)$.

The same reviewer also mentions that the following example makes a nice near-minimal pair to (13b), since it contains an indefinite:

(i) Every cyclist met Lance, who carried with him a Tour de France souvenir. 
Supplemental update

by the use of in turn. In (12b), the scope of the apposition is unconstrained, and so the projective interpretation is available.

\subsubsection{Scope preferences}

It remains to explain why certain scopings are preferred for supplements, so that they get the projective reading if possible. Nouwen (2014) proposes that competing representations of supplements are ranked so that a wider-scope representation is always preferred to a narrower-scope one. In a similar vein, AnderBois, Brasoveanu \& Henderson (2015) model supplements as updating the discourse context directly, using a different update mode from the proposal generated by the surrounding main clause content. For AnderBois, Brasoveanu \& Henderson, a supplement forces its anchor to always take widest scope, and apparent exceptions such as (7), (10), or

(15) If a professor, a famous one, publishes a book, he will make a lot of money.

(Wang, Reese \& E. McCready 2005: (2b))

are instances of “one-asides”, and treated differently from true appositives. In their approach, the apparent ability of such one-asides to take narrow scope is explained by construing them are mere corrections, comments on the immediately preceding anchor.

Nouwen (2014) offers some compelling arguments suggesting that an analysis of examples like (15) as corrections is inadequate. But those arguments notwithstanding, there are independent reasons to doubt that AnderBois, Brasoveanu \& Henderson's approach is empirically justified, since it is not difficult to find examples of nonprojecting supplements that are not one-asides, for example, (8), (12a), (13b), or the adaptation of (10) in

(16) Every famous boxer I know $i$ has a devoted brother, who he $e_{i}$ completely relied on back when he ${ }_{i}$ was just an amateur.

To avoid the appearance of basing generalizations about the data solely on what Pereira (2013) has called "overeducated introspection", I also note the following naturally occurring example of a nonprojecting supplement:

(17) But there would always be some student, a photographer or a glassblower, who would simply have taken a piece of newspaper and folded it once and propped it up like a tent and let it go at that. ${ }^{3}$

3 From Bauhaus to Our House, by Tom Wolfe, p. 11. Farrar, Straus and Giroux, 1981. 
The interpretation of (17) resembles the one for (8): on each occasion, some different student, who by the way was a photographer or glassblower, would fold a newspaper a certain way. These examples illustrate the problem with AnderBois, Brasoveanu \& Henderson's requirement that supplements always take widest scope. For (8), (13b), and (16), if the supplement is in widest scope position, it cannot update the context directly without the bound variable becoming unbound, so that the account predicts an unobserved infelicity. For (12a) and (17), the widest-scope supplement reading requires its anchor to also take widest scope, resulting in truth conditions that do not correspond to intuitions.

Taking a different tack, Schlenker (2013a, 2013b) attempts to explain the scoping preference for supplements on the basis of a more general pragmatic principle called Translucency. Under this principle, it should be possible to add uncontroversial assumptions to a supplement's context of interpretation that make its semantic content "locally trivial", that is, entailed by the context. However, it is not hard to produce examples of supplements for which Translucency seems not to apply. For instance, in (12b) it does not seem that the apposition a total jerk represents an uncontroversial assumption about the chair. Similarly, in (10), it does not seem that the speaker is inviting her interlocutors to make an uncontroversial assumption that whoever coaches every boxer is necessarily famous. And the assumption that Lance is a (cheating) doper does not seem uncontroversial in (13c).

To explain why supplements with an indefinite anchor can more easily take narrow scope (i.e., fail to project) than ones with a definite anchor, I propose that a supplement's scope, and therefore its projection, is in part determined by independent scope preferences related to its anchor. One factor influencing these preferences is that an anaphoric trigger is interpreted as closely as possible to the site of its antecedent. This idea surfaces in the theory of anaphora due to van der Sandt (1992) and Geurts (1999), refined and implemented by Blackburn \& Bos (1999) and Bos (2003), in the following way: when a definite is resolved, it traverses the history of accessible discourse contexts to find a suitable antecedent, incorporating its descriptive content at the site of the antecedent. Barker \& Shan (2014: chapter 15) echo this idea in their analysis of parasitic scope, with pronouns taking scope immediately under their antecedents. It also shows up in Roberts's (2003) weak familiarity, a generalization of the notion of Heim's (1982) familiarity in which a suitable antecedent need only be entailed to exist, but not necessarily 
Supplemental update

overtly mentioned. In (18), for example, the antecedent to it is only weakly, but not strongly, familiar:

(18) Every motel room has a copy of the Bible in it. In this room, it was hidden under a pile of TV Guides.

(Heim 1982, discussed by Roberts 2003: 297 as (15))

According to Roberts's account, the antecedent for it in (18) is available because it is entailed to exist: this room is interpreted to be a motel room, and, as the first utterance implies, being a motel room entails having a copy of the Bible. Proper names, modeled as a subclass of anaphoric triggers, following Geurts (1999), Beaver (2001), and Martin (2013), inherit the behavior of definites more generally. This lines up with the treatment of proper names in Discourse Representation Theory, where they correspond to discourse referents in the top level (i.e., widest scope) of the representation (Kamp \& Reyle 1993, Bos 2003).

In this characterization of definite anaphora, the process of interpreting a discourse is viewed as a sequence of contexts resulting from the series of updates generated by its component utterances. More concretely, modeling a discourse as a series of dynamic meanings $m_{0}, m_{1}, \ldots$ gives rise to the sequence of contexts $c_{0}, c_{1}, \ldots$ as follows:

$$
c_{0} m_{0} c_{1} m_{1} c_{2} \cdots
$$

This model starts with the context $c_{0}$, which is then updated by $m_{0}$ to produce the context $c_{1}$, in turn updated to produce $c_{2}$ by $m_{1}$, etc. Definites, in this proposal, prefer to take their scope at the earliest possible position in the chain of contexts produced by interpreting the discourse, other things being equal. That is, if a suitable antecedent for some definite $d$ is introduced by $m_{i}$, then the position immediately after $m_{i}$ is preferred as a scoping site for $d$ to every $m_{j}$ where $i<j$.

This proposal thus captures the observation that appositions anchored to definites obligatorily project, except when constrained by discourse anaphora, as in (13b). To demonstrate, note the contrast between the following:

(12b) If tomorrow I call the chair, a total jerk, then we will be in deep trouble.

(13c) Every cyclist met Lance, a doper who cheated to win the Tour de France.

(19) a. It's not true that Lance, a doper, won the Tour de France.

b. It's not true that some cyclist, a doper, won the Tour de France. 
For (12b), the preference for the projective reading is predicted because the anchor of the appositive a total jerk is anchored by the chair, which scopes widest because its antecedent occurs outside the current utterance. Because of this, the supplement's implication that the chair is a jerk is outside the scope of the conditional, as observed. Similarly, in (13c), the proper name Lance is the anchor for the appositive whose content is that he is a doper who cheated to win the Tour. Since proper names are treated as instances of definites, Lance must find its antecedent outside of the utterance in (13c), and therefore scopes wide relative to the quantifier Every, yielding the observed projective reading. For (19a), the implication that Lance is a doper likewise escapes the effects of negation. But an available reading of (19b) is the one reflected in the surface order of the negation and supplement, equivalent to It's not true that some doping cyclist won the Tour de France.

There is also a difference observed in the scope preferences for (19b) and the variant of (1a) in

(20) Some cyclist, a doper, didn't win the Tour de France.

For (19b), where the negation's surface position precedes the supplement's, it seems that a negation-wide interpretation is more readily available than for (20), where the supplement precedes the negation. I propose that this is simply an instance of the well-known default preference for operators to take surface scope. Importantly, the inverse scope reading for (19b) is still possible, namely, the one where there is some doping cyclist who didn't win the Tour, the surface scope reading of (20). Since the anchor, in both of these cases, is an indefinite, it is not subject to the same widest-scope preference as definite anchors, because indefinites do not seek an antecedent in prior context.

Of course, the anchor's properties are not the only factors influencing supplement projection.

(21) $\mathrm{John}_{i}$ didn't read a book, which Mary had recommended to him . $_{\text {. }}$ (AnderBois, Brasoveanu \& Henderson 2015: 31, (72); indices mine)

Here, the indefinite $a$ book seems to counteract both the default preference for the proper name to scope widest and for the negation's scope to reflect its wider surface position. Cases like (21) and (22), below, show that contextual factors and world knowledge can also impact the scope of a supplement's anchor.

(22) NASA's Mars Curiosity rover didn't find an alien, who was green and scaly, roaming the surface. 
Supplemental update

This account predicts that the indefinite's scope is preferred to be narrow for both (21) and (22), other things being equal, although a widest-scope indefinite reading is still possible. This treatment seems to be correct for (22), where the indefinite is difficult to interpret as taking widest scope because of default assumptions about the existence of aliens on Mars, whereas for (21), the widest-scope indefinite reading is much more available. As for the supplement's preference to scope wide in (21), it is possible that pragmatics plays a role, since the use of the comma intonation distinguishes (21) from

(23) $\mathrm{John}_{i}$ didn't read a book which Mary had recommended to him .

The alternative in (23) contains a restrictive relative clause variant of the supplement in (21) that more easily takes narrow scope. I leave the influence of context and the availability of alternatives on supplement projection as questions for future research.

\subsubsection{Quantified supplements and telescoping}

The inability of certain appositives to anchor to a true quantifier has been taken as evidence that supplements obligatorily project.

(24) \#Every Dutch boxer, a famous one, took part in the event. (Nouwen 2007: 87, (2))

(25) \#No climber, $\left\{\begin{array}{l}\text { an } \\ \text { the }\end{array}\right\}$ experienced adventurer, was found sipping hot cocoa in the lodge.

(Potts 2005: 122, (4.73a))

The supplement in (24) cannot be interpreted so that every Dutch boxer is famous, and similarly, (25) does not mean that no climber was an experienced adventurer. However, as Nouwen (2007) notes, this pattern is not completely general.

(26) Every climber, all experienced adventurers, made it to the summit. (Potts 2005: 124, (4.75))

Example (26) shows that the quantifier Every can sometimes play the role of the determiner in a supplement anchor after all. Nouwen argues for an analysis in which true quantifiers can anchor supplements when the apposition is plural. 
But the data are still more subtle, since it is clear from the following examples that a quantifier can sometimes bind a pronoun in a supplement that is interpreted outside the quantifier's scope.

(27) No Tibetan Buddhist ${ }_{i}$ thinks the Dalai Lama, his ${ }_{i}$ spiritual mentor, would ever cave to Chinese pressure tactics.

(Carl Pollard, personal communication)

(28) $\left\{\begin{array}{l}\text { Every } \\ \text { No }\end{array}\right\}$ Democratic president ${ }_{i}$ thinks the right-wing press, his p $_{i}$ sworn enemy, will give him $_{i}$ fair and balanced treatment.

(29) Every business owner I know ${ }_{i}$ wants the Wall Street Journal ${ }_{j}$, which is naturally his $_{i}$ favorite newspaper, to expand its ${ }_{j}$ editorial page.

These examples all show a supplement that contains a bound pronoun but also projects, in contrast to (13b). In (27), the singular pronoun his is bound by No Tibetan Buddhist, indicating that the supplement is interpreted in its scope. But there is a reading of (27) that implies that every Tibetan Buddhist's spiritual mentor is the Dalai Lama, in which the supplement is taken to project. Similarly, both variants of (28) have an interpretation in which for each Democratic president $x$, the right-wing press is $x$ 's enemy, even though the pronoun his is anteceded by $x$, which is bound by a quantifier. And likewise, (29) implies that the Wall Street Journal is the preferred newspaper of every business owner I know independently of the fact that they all want it to expand its editorial page.

Examples like those in (27)-(29) can also be adapted to provide further evidence that the pattern in (24) and (25) does not hold in general.

(30) No Tibetan Buddhist ${ }_{i}$, the Dalai Lama ${ }_{j}$ his $_{i}$ spiritual mentor, thinks that esteemed $\operatorname{man}_{j}$ would ever cave to Chinese pressure tactics.

(31) Every Democratic president ${ }_{i}$, (with) the right-wing press (being) his ${ }_{i}$ sworn enemy, refuses to give an interview to Fox News.

(32) Every business owner I know ${ }_{i}$, his $s_{i}$ favorite newspaper naturally the Wall Street Journal ${ }_{j}$, wants it ${ }_{j}$ to expand its ${ }_{j}$ editorial page.

Each of these examples contains a supplement anchored by a true quantifier, and each has the same projective reading as its respective counterpart in (27)-(29). To show that these are not just cooked up to make a point, the following is a similar instance of this phenomenon in the wild: 
Supplemental update

(33) For several years there was no president, his duties being discharged by the professors in turn. ${ }^{4}$

Part of the interpretation of (33) is the implication that the duties that would normally have been handled by a president were instead handled by various faculty members during a certain period, and this implication is separate from the implication that there was no president for several years.

With appositives modeled as QP modifiers, examples (27)-(29) seem to pose a problem for the current proposal, because it construes a supplement's scope as identical to its anchor's scope. But note the similarity between the interpretation of the supplement in the projective reading of (27) and the phenomenon of telescoping (Roberts 1989, 2005, Wang, E. McCready \& Asher 2006):

(34) Each degree candidate ${ }_{i}$ walked to the stage. $\mathrm{He}_{i}$ took his ${ }_{i}$ diploma from the dean and returned to his ${ }_{i}$ seat.

(Roberts 1989: 717, (34))

In (34), the pronouns $\mathrm{He}$ and his are anteceded by a discourse referent introduced in the scope of Each, which normally limits the accessibility of referents in its scope. This is similar to what we observe in (27), where it seems possible for the apposition his spiritual mentor to be interpreted both within and outside of the scope of No. Accordingly, I classify examples like (27)-(29) as special cases of telescoping, not as counterexamples to this proposal. I return to this point in Section 3.4.3, below, where I detail the formal analysis of (27).

\subsection{Anaphora and deniability}

In addition to their scope-taking capabilities, there is clear evidence that supplements are sometimes sensitive to their linear ordering relative to surrounding content, and should therefore not be treated as a kind of noble gas of senses, immune to the usual semantic processes. For instance, the possibilities for anaphoric links appear to be the same for supplements as they are for other content, as Amaral, Roberts \& Smith (2007), AnderBois, Brasoveanu \& Henderson (2010, 2015), Koev (2014), and Martin (2013) doc-

4 From The American Cyclopaedia, by George Ripley and Charles A. Dana. D. Appleton and Company, 1873. Retrieved from chestofbooks.com/reference/American-Cyclopaedia3/Columbia-College.html on April 10, 2014. 
ument. Some examples illustrating anaphora between a supplement and surrounding content are (8), (13b), (16), and

(35) $\mathrm{Kim}_{i}{ }^{\prime}$ s bike $_{j}$, which used to have reflectors ${ }_{k}$ on it ${ }_{j}$, was pretty safe to ride at night until she ${ }_{i}$ decided to take them ${ }_{k}$ off.

This example shows anaphora both into and out of an apposition in a single utterance: the discourse referent for Kim's bike antecedes a pronoun in the apposition, and the referent for the reflectors it used to have, which is introduced within the apposition itself, is the antecedent for the pronoun them occurring in the main clause content following it. And these interactions are also not limited to definite anaphora:

(36) John, who has two motorcycles, wants his wife to get one too.

(Amaral, Roberts \& Smith 2007: 741, (37))

Here, the iterative adverb too is licensed by John's having a motorcycle, information that arises from within the supplement's apposition. Ellipsis can also take place between supplement and nonsupplement content, as Giorgolo \& Asudeh (2012) and AnderBois, Brasoveanu \& Henderson (2015) show.

The following examples give further evidence of the parallels between anaphora in the supplement case and discourse anaphora more generally.

(37) a. Lance gave a bike ${ }_{i}$ to Kim, and she loved it $_{i}$.

b. ?Kim loved it ${ }_{i}$ and was given a bike ${ }_{i}$ by Lance.

(38) a. Lance gave a bike ${ }_{i}$ to Kim, who loved it ${ }_{i}$.

b. ?Kim, who loved it ${ }_{i}$, was given a bike ${ }_{i}$ by Lance.

In both (37a) and (38a), we see unproblematic instances of discourse anaphora: an antecedent for a bike is introduced which is later selected by the pronoun it. But (37b) and (38b) show that cataphora is dispreferred both for the supplement and nonsupplement case.

AnderBois, Brasoveanu \& Henderson (2010, 2015) and Koev (2012) argue that supplements can be more easily denied when they occur finally within an utterance.

(39) a. He told her about Luke, who loved to have his picture taken.

b. No, he didn't like that at all.

c. No, he told her about Noah.

(AnderBois, Brasoveanu \& Henderson 2010: 342, (48)) 
Supplemental update

In (39), both the nonsupplement content and the supplement can be directly denied. And Schlenker (2013b) presents examples that suggest that supplement deniability is more gradient than a simple categorical distinction between final and nonfinal occurrence.

(40) a. i. The first lady got introduced to Lance, who was at the White House.

ii. No he wasn't; they met in a restaurant.

b. i. Ann introduced Lance, who was at the White House, to the first lady.

ii. ?No he wasn't; they met in a restaurant.

c. i. Lance, who was at the White House, got introduced to the first lady.

ii. ??No he wasn't; they met in a restaurant.

(Schlenker 2013b: 47, (105))

The judgments are subtle in these cases, but it seems clear not only that (40c) is more marginal than (4Oa), as AnderBois, Brasoveanu \& Henderson (2010, 2015) and Koev (2012) also claim, but also that (40b) is somewhat less marginal than (40c).

Note the similarity between the influence of a supplement's linear position on its deniability and the effects of linear order on the relative salience of antecedents for anaphora. In (40a), the proposal that Lance was at the White House can be readily challenged by No, he wasn't, whereas in (4ob) and (40c), the follow-up No he wasn't; they met in a restaurant seems to be required to clarify that it is the supplement that is being challenged. Thinking of an utterance containing a supplement as constituting a series of separate proposals, Ginzburg's (2012) analysis of denials as targeting the most salient proposition in the discourse context explains the difference in deniability between utterance-final and utterance-medial supplements. Extending Ginzburg's analysis to the case of supplements, the proposal corresponding to the supplement in (40a) is more salient than the ones in (40b) and (40c) because it occurs more recently.

The similarity with anaphoric salience is illustrated by

(41) A cowboy $_{i}$ walked in and sat down. Another cowboy ${ }_{j}$ walked in, and he $_{\# i / j}$ ordered a double bourbon.

Although not the sole determinant of salience for anaphoric antecedents, recency is clearly an important factor, as (41) shows. In this example, the 
pronoun he cannot be construed as being anteceded by the first cowboy mentioned, but only by the second. To force the less recently mentioned cowboy as the antecedent, the first cowboy would have to be used instead of he, just as No he wasn't; they met in a restaurant is needed to target the supplement in (40c).

I claim, following Koev (2012), that the presence of a supplement in a matrix clause generates two separate proposals: one containing only the supplement's content, and the other containing the surrounding content. The resulting proposals are ordered based on their linear position within the utterance that gave rise to them, so that (40a) generates the sequence of proposals The first Lady got introduced to Lance. He was at the White House, while (40c) generates Lance was at the White House. He got introduced to the first lady. Then, just as for anaphoric salience, the effect of recency of mention on the relative salience of proposals postulated by Ginzburg (2012) helps explain the greater deniability of the supplement in (40a) in comparison to the one in (4OC).

\section{Formalizing the account}

The formal account is detailed starting below in Section 3.2, but first, the intervening section lays out some technical preliminaries required for the analysis. Many of the relevant technicalia are distilled in the appendix; references to sections and definitions found there are prefixed with A.

\subsection{Preliminaries}

The dynamic semantics used here extends the Agnostic Hyperintensional Semantics (AHS) of Pollard (2008, 2015), which uses the nonlogical type p of propositions as the type of declarative sentence meanings. AHS is agnostic in the sense that it does not take a position on whether propositions are defined as sets of worlds or in some other, more suitable way. The logical truth-value type $t$ is used as the extension type of propositions, and counterparts of all of the usual boolean connectives and quantifiers are axiomatized at the level of propositions (see, in particular, Definitions A.2 and A.7).

The main distinction between AHS and standard possible worlds semantics is that nothing in AHS requires mutually entailing propositions to be identical, avoiding some notorious foundational problems plaguing standard approaches. Although the account does not hinge on the use of AHS, it lets 
Supplemental update

us avoid defining an extensional fragment, or, alternatively, stipulating that intensional predicates are silently provided with some nonce world argument. This extension of AHS is both compositional and dynamic, in the tradition that includes Muskens (1994, 1996), Beaver (2001), de Groote (2006), and Martin \& Pollard (2012a,b). Martin (2013: chapters 3 and 4) and Martin \& Pollard (2014) describe this semantics in much greater detail; see the appendix for more.

Dependent types parameterized by the natural numbers are used to track the number of discourse referents available in a given context. Contexts are modeled via the type $\mathrm{c}_{n}={ }_{\text {def }} \mathrm{e}^{n} \rightarrow \mathrm{p}$, as functions from an $n$-ary vector of entities to a proposition (cf. Definitions A.8-A.10). This notion of a context derives from Stalnaker (1978) and Lewis (1979), with the discourse context consisting of the contributions of prior utterances, and represented formally by a single conjoined proposition. Using this simplified, though somewhat unrealistic, context model enables the analysis to focus on those aspects of dynamic interpretation that are central to describing the anaphoric capabilities of supplements.

The natural number coordinates of a context's input vector play the role of discourse referents in the dynamic tradition, with the idea that the interlocutors in general do not know the identities of the referents being discussed. These entity vectors can therefore be thought of as analogous to Heim's (1982) "sequences", or to the role played by assignments in Dynamic Predicate Logic (Groenendijk \& Stokhof 1991). The proposition that results from applying a context to an entity vector of suitable length contains the information that is known about the discourse referents in the input vector. For example, a context modeling the contribution of an utterance like Some cyclist owns a bike would be

$$
\left.\left.\lambda_{x, y} .(\text { cyclist } x) \text { and (bike } y\right) \text { and (own } y x\right): \mathrm{c}_{2},
$$

where the bound variable $x, y$ represents a two-coordinate vector of entities (this notational convention, and others, is discussed in Section A.1). In this model, indefinites are not quantificational, reflecting one of the fundamental insights of dynamic semantics that dates back to Kamp (1981) and Heim (1982). The arity of an $n$-ary context $c$, written $|c|$, is defined to be $n$, which is intuitively the number of discourse referents the context is about.

The meanings of declarative utterances have the type $\mathrm{k}_{n}={ }_{\text {def }} \mathrm{C}_{m} \rightarrow \mathrm{c}_{m+n}$, of contents, the type of functions from contexts to contexts that introduce $n$ discourse referents (Definition A.11). The dynamic connectives and quanti- 
fiers, detailed in Section A.5, are defined to capture all of the core insights of dynamic semantics: the conjunction AND is asymmetric, with the second conjunct interpreted in the context obtained by updating the input context with the first conjunct; the operator EXISTS introduces a new discourse referent but does not quantify over anything; the negation NOT traps any discourse referents introduced in its scope, making them unavailable for future reference, etc.

\subsection{Basic ingredients of the analysis of supplements}

Since the semantics it is expressed in has built-in capabilities for both discourse anaphora and operator scope, this analysis only needs to characterize the dynamic meaning of the comma intonation that surrounds appositions. As a prelude to formally defining the comma intonation, we first need to introduce machinery to handle some of its ingredients.

One ingredient, the process of predicativization, is needed independently of an analysis of supplements, for instance, in modeling copular expressions. The predicativizer PRED : $\left(\mathrm{d}_{1} \rightarrow \mathrm{k}\right) \rightarrow \mathrm{d}_{1}$, defined in (A.12), turns a dynamic GQ into a dynamic property with the type $d_{1}$, the type of functions from a natural number (i.e., a discourse referent) to a content, modulo type dependencies (cf. Definition A.17). For example, applying the predicativizer to the GQ A CYCLIST gives the following dynamic property:

$$
\begin{aligned}
(\text { PRED A CYCLIST }) & =\lambda_{n: \mathrm{n}} \cdot\left(\text { A CYCLIST }_{m} \cdot m \text { EQUALS } n\right. \\
& =\lambda_{n: \mathrm{n} \cdot} \cdot \text { EXISTS }_{m} \cdot(\text { CYCLIST } m) \text { AND }(m \text { EQUALS } n)
\end{aligned}
$$

The dynamic indefinite determiner $\mathrm{A}$ is defined in (A.13), and the dynamic property

$$
\text { CYCLIST } \left.=_{\text {def }}\left(\text { dyn }_{1} \text { cyclist }\right)=\lambda_{n: \mathrm{n}} \lambda_{c: c>n} \lambda_{\mathbf{x}^{|c|}} \text {. (cyclist } x_{n}\right)
$$

is derived from its corresponding static property cyclist (see Definition A.18).

Another independently motivated ingredient of this analysis is proper names, which can serve as supplement anchors. In order to give a uniform treatment of the comma intonation, I follow Beaver (2001) and Martin (2013) in treating proper names on a par with other definites, as generalized quantifiers. For example, the dynamic meaning of a proper name like Kim is

$$
\mathrm{KIM}=_{\text {def }}(\text { THE NAMED-KIM }),
$$

where the generic definite determiner THE is defined in (A.18), and NAMED-KIM is the dynamic property of being named "Kim". Thus a proper name is essen- 
Supplemental update

tially analyzed as a GQ whose restrictor anaphorically selects the contextually unique, most salient discourse referent entailed to have the relevant name. As for salience itself, although the entity vectors representing the active discourse referents in a context are necessarily ordered by recency (cf. Definitions A.9 and A.20), a full implementation of salience is left outside the account because it involves so many complex and disparate factors.

\subsubsection{Making an at-issue proposal}

The context change function cc, defined in (A.3) and mnemonically named to evoke Heim's (1982) context change potentials, promotes a content to an $n$-degree update that also introduces $n$ discourse referents, but additionally incorporates the information from the input context into its output (cf. Definition A.12). An important aspect of the account is that a widest-scope supplement gives rise to a separate at-issue proposal. By way of making this notion more concrete, updates model proposals that can be accepted or rejected by the discourse participants. Then the act of proffering a content (Roberts 2012a,b) is modeled by promoting it to a proposed update, or simply proposal, via the context change function. That is, if $k$ is the content representing the dynamic meaning of an utterance, then its corresponding proposal is the update (cck).

Discourse parataxis is modeled by the operation $\circ$, which composes two updates; it is defined in (A.9). An important fact relating cc, AND, and $\circ$ is the following:

Theorem A.2 (Conjoined update is equivalent to parataxis).

$$
\vdash \forall_{h: k} \forall_{k: k} \cdot \mathrm{cc}(h \text { AND } k)=(\mathrm{cc} h) \circ(\mathrm{cc} k) \text {. }
$$

This relationship is central to the account of supplement projection, since it states that a proposal consisting of a conjoined update is equivalent to a series of two proposals, one for each of the conjuncts. A proof is given in the appendix.

\subsubsection{The comma intonation}

Now all the ingredients are in place for defining the comma intonation. To help motivate and illustrate the definition, I repeat from above the breakdown of the component parts of the supplement in 
(1a) $\overbrace{\text { Some cyclist }}^{Q}, \overbrace{\text { a doper }}^{D}, \overbrace{\text { won the Tour de France. }}^{E}$

As discussed above, the supplement in (1a) has a QP $Q$ into which an extra property denotation, the apposition in $D$, gets smuggled. This property supplements the usual scope argument to the QP, here represented by $E$.

With this characterization in mind, the dynamic meaning of the comma intonation is COMMA : $\left(\mathrm{d}_{1} \rightarrow \mathrm{k}\right) \rightarrow \mathrm{d}_{1} \rightarrow \mathrm{d}_{1} \rightarrow \mathrm{k}$, which takes a generalized quantifier meaning (type $\mathrm{d}_{1} \rightarrow \mathrm{k}$ ) and a dynamic property (type $\mathrm{d}_{1}$ ) to another generalized quantifier meaning. Its definition is

$$
\text { COMMA } \left.=_{\text {def }} \lambda_{Q D E} \cdot(Q D) \text { AND (THE } D E\right) .
$$

Here, the meanings of dynamic conjunction AND and the definite determiner THE are respectively defined in (A.4) and (A.18) in the appendix.

The definition in (A.27) is fairly complex, and the best way to demonstrate how it works is to go through some examples. But briefly note what COMMA does: it takes a dynamic GQ $Q$ and a predicativized apposition $D$, applying $Q$ to $D$ as its scope. It then dynamically conjoins the result with the application of the verb phrase property $E$ to the uniquely most salient discourse referent which has the apposition property $D$. It is this sense in which appositions are analyzed as QP modifiers: their semantic content is integrated directly into the QP that is the first argument to COMMA. This allows us both to retain a generalized quantifier treatment of noun phrases (Barwise \& Cooper 1981, Keenan \& Stavi 1986) and to immediately impart the anchor's scope to the supplement, since they are inextricably bound.

To better connect this treatment of the comma intonation to intuitions, consider the analysis it would produce for (1a). With the dynamic meanings of the properties corresponding to cyclist, doper, and won the Tour de France defined via dyn ${ }_{1}$ (cf. Definition A.18), we first pass the GQ Some cyclist as the first argument to COMMA.

$$
\frac{(\text { A.27 })}{\vdash(\text { COMMA (A CYCLIST) }): \mathrm{d}_{1} \rightarrow \mathrm{d}_{1} \rightarrow \mathrm{k}}
$$

We then apply the predicativizer (A.12) to the apposition content.

$$
\text { (43) } \frac{\vdash \text { PRED }:\left(\mathrm{d}_{1} \rightarrow \mathrm{k}\right) \rightarrow \mathrm{d}_{1} \frac{\vdash \mathrm{A}: \mathrm{d}_{1} \rightarrow \mathrm{d}_{1} \rightarrow \mathrm{k} \quad \vdash \text { DOPER }: \mathrm{d}_{1}}{\vdash(\text { PRED A DOPER }): \mathrm{d}_{1}}}{\vdash \text { DOPER }: \mathrm{d}_{1} \rightarrow \mathrm{k}}
$$

Then this predicativized apposition content can be taken as the comma intonation's second argument: 
Supplemental update

$\frac{(42)}{\vdash(\text { COMMA (A CYCLIST) (PRED A DOPER) }): \mathrm{d}_{1} \rightarrow \mathrm{k}}$

In (44), we have derived a dynamic GQ into which the semantic content of both the restrictor cyclist and the apposition a doper have been integrated. Now this quantifier takes the verb phrase's denotation as its argument to give a meaning for (1a).

$$
\frac{(44)}{\vdash \text { (COMMA (A CYCLIST) (PRED A DOPER) WIN-TDF) }: \mathrm{k}}
$$

The semantics derived in (45) reduces as follows:

$$
\begin{aligned}
& \text { COMMA (A CYCLIST) (PRED A DOPER) WIN-TDF } \\
& =(\text { A CYCLIST }(\text { PRED A DOPER })) \text { AND (THE (PRED A DOPER) WIN-TDF) }
\end{aligned}
$$

By Theorem A.2, the proposal that results from applying cc to the content derived in (45) is equivalent to a sequence of two proposals:

(46) CC ((A CYCLIST (PRED A DOPER) ) AND (THE (PRED A DOPER) WIN-TDF))

$$
=\mathrm{CC}(\mathrm{A} \text { CYCLIST }(\text { PRED A DOPER })) \circ \mathrm{CC}(\text { THE }(\text { PRED A DOPER }) \text { WIN-TDF })
$$

That is, with the operation $\circ$ modeling discourse parataxis, proposing (1a) is equivalent to proposing the two-utterance discourse Some cyclist is a doper. The doper won the Tour de France. Because it allows supplement content to be separated into its own proposal, this equivalence enables both supplement projection and deniability, discussed below in Section 3.4. Importantly, a supplement occurring in an unembedded position, as in (1a), is predicted to always project, because the widest scoping is the only one available. With supplements modeled as QP modifiers, an analysis of supplement "stacking" (Potts 2005: 100) is also possible; Martin (2015) gives a thorough analysis of supplement syntax, including the phenomenon of stacking. ${ }^{5}$

5 A reviewer points out that some cases of stacking may pose a problem for this account, since the anaphoric reference in the comma intonation may become confused by multiple possible antecedents, as in

(i) Some cyclist, who doped, as a doper told me, won the Tour de France.

A model of (i) in this account would have to deal with the fact that the anaphorically selected subject of the verb phrase won the Tour de France would have to decide between two competing doper antecedents. I propose that the mechanism that determines salience would be sensitive to cases like these, as it would need to be independently to handle examples like

(ii) If a cyclist ${ }_{i}$ has a doping doctor ${ }_{j}$, he $_{i}$ always knows where to find him $_{j}$.

Here, both pronouns need to choose between the two potential antecedents, but there is a preference, indicated by the indices, for the chosen antecedents to override recency in favor 
I briefly examine how the anaphoric element of the comma intonation functions in utterances containing multiple supplements.

(47) Some cyclist, a doper, accused a boxer, a doper, of cheating. ${ }^{6}$

After generating the required dynamic properties corresponding to boxer and accused of cheating via $\mathrm{dyn}_{1}$, we get the following semantics for (47):

$$
\begin{aligned}
& (\text { COMMA }(\text { A CYCLIST })(\text { PRED A DOPER }))_{n} \cdot \\
& (\text { COMMA }(\text { A BOXER })(\text { PRED A DOPER }))_{m} \text {.ACCUSE } m n
\end{aligned}
$$

This content reduces to

(A CYCLIST (PRED A DOPER)) AND (THE (PRED A DOPER)

$$
\left.\left.\lambda_{n} \text {. (A BOXER (PRED A DOPER) ) AND (THE (PRED A DOPER }\right)\right)_{m} \text {.ACCUSE } m \boldsymbol{n} \text { ) . }
$$

Assuming a model of salience that is sensitive to recency of mention, which I do not develop formally here, both instances of THE in this semantics of (47) would access the more recently mentioned doper, giving the desired reading.

\subsubsection{Non-restrictive relatives and $a s$-parentheticals}

So far, this semantics only models nominal appositives (NAs), a subclass of supplement constructions. But extending it to the cases of nonrestrictive relatives (NRRCs) and as-parentheticals (APs) is straightforward. The nonrestrictive relativizer who, parenthetical as, and the predicative copula is, translated respectively as $\mathrm{WHO}_{\mathrm{nrrc}}, \mathrm{AS}_{\text {paren }}$, and $\mathrm{IS}_{\text {pred }}$, are all defined as the identity function on dynamic properties $\lambda_{D} . D: \mathrm{d}_{1} \rightarrow \mathrm{d}_{1}$. Then for a variant of (1a) with a NRRC like who is a doper substituted for the NA a doper, we can derive

$$
\mathrm{WHO}_{\text {nrrc }}\left(\mathrm{IS}_{\text {pred }}(\text { PRED A DOPER) })\right.
$$

to represent the NRRC who is a doper. Then this meaning could be spliced into the proof in (44) in place of (43) to give the content

$\vdash$ COMMA (A CYCLIST) $\left(\right.$ WHO $_{\text {nrrc }}\left(\right.$ IS $_{\text {pred }}($ PRED A DOPER $\left.\left.)\right)\right)$ WIN-TDF $: \mathrm{k}$.

of syntactic parallelism. For (i), the salience mechanism would need to rank the first, less deeply embedded, doper over the second. As the reviewer notes, invoking salience to choose the proper antecedent in (i) additionally requires it to make a categorical distinction in order to avoid spurious ambiguity, since an ambiguity exists for (ii) that is not observed in (i).

6 Thanks to the same reviewer who supplied (i) in footnote 5 for also pointing out this example, as well as (52) and (53). 
Supplemental update

Note that since both $\mathrm{WHO}_{\text {nrrc }}$ and IS $\mathrm{S}_{\text {pred }}$ are defined as the identity function, this semantics equivalent to the one derived in (45).

The story is similar for the case of APs. A semantics representing as a doper,

$$
\text { AS paren (PRED A DOPER), }
$$

can be straightforwardly derived and used as the predicativized argument to the comma intonation in place of an NA or NRRC. Of course, lexical entries would need to be defined to rule out derivations of ungrammatical strings like * as who is as a doper via syntactic type constraints. I ignore this complication here, since the point is simply to show that the analysis does not just apply to NAs but to supplements more generally. This analysis may be too coarsely grained, since it predicts that NAs, NRRCs, and APs always receive parallel treatment. The main purpose of these potentially incomplete definitions is to extend the analysis to NRRCs and APs. See Martin 2015 for a more indepth consideration of the syntax-semantics interface for the various types of supplements discussed here.

\subsection{Anaphora out of and into supplements}

In this account, supplements are no different than other content in terms of their potential both to contain anaphoric triggers and to host antecedents for later anaphora. The following simple example demonstrates an indefinite in an apposition introducing a discourse referent that is later referenced by a pronoun.

(48) Melanie, who adores an $\operatorname{Italian}_{i}$, bought himi ${ }_{i}$ a present.

(Koev 2014: (2))

To model this example, we define the proper name Melanie as the dynamic GQ MELANIE, similarly to KIM in (A.20), and the required dynamic properties by applying the relevant dyn function from Definition A.18. These definitions allow a derivation of the semantics for (48):

$$
\begin{aligned}
& \left(\text { COMMA MELANIE }\left(\mathrm{WHO}_{\mathrm{nrrc}} \lambda_{n} \cdot(\text { A ITALIAN })_{m} \text {.ADORE } m n\right)\right. \\
& \left.\lambda_{n} \cdot \mathrm{HIM}_{m} \cdot(\text { A PRESENT })_{k} \cdot \text { BUY } k m n\right)
\end{aligned}
$$

The reduction of (49) below helps to illustrate how the anaphoric link between him and an Italian is established.

$\left(\right.$ MELANIE $_{n} \cdot(\text { A ITALIAN })_{m}$.ADORE $m n$ ) AND

$\left(\operatorname{THE} \lambda_{n} \cdot\left((\text { A ITALIAN })_{m} \cdot \operatorname{ADORE} m n\right) \lambda_{n} \cdot \operatorname{HIM}_{m} \cdot(\text { A PRESENT })_{k} \cdot\right.$ BUY $\left.k m n\right)$ 
As this reduction shows, the dynamic conjunction AND passes a context containing a new discourse referent for the Italian Melanie adores to the second conjunct, where it can be picked up by HIM, defined in (A.22).

In the following example, a variation of (13b), the pronoun him in the apposition is anteceded by Some cyclist, which occurs in the surrounding nonsupplement content.

(50) Some cyclist ${ }_{i}$ met Lance, who gave himi $i$ a souvenir.

This example, too, can be modeled via the standard anaphora machinery, as

$$
\begin{aligned}
& \left(\text { COMMA LANCE } \lambda_{n} \cdot(\text { A CYCLIST })_{m} \cdot(\text { MEET } n m)\right. \\
& \left.\left(\text { WHO }_{\text {nrrc }} \lambda_{n} \cdot \text { HIM }_{m} \cdot(\text { A SOUVENIR })_{k} \cdot \text { GIVE } k m n\right)\right),
\end{aligned}
$$

where LANCE is defined similarly to KIM, and the necessary dynamic properties are generated by dyn as before. This semantics reduces to

$\left(\right.$ LANCE $_{n} \cdot\left(\mathrm{A} \mathrm{CYCLIST}_{m} \cdot \operatorname{MEET} n m\right)$ AND

$\left(\operatorname{THE} \lambda_{n} \cdot(\text { A CYCLIST) })_{m} \cdot(\operatorname{MEET} n m) \lambda_{n} \cdot \operatorname{HIM}_{m} \cdot(\text { A SOUVENIR })_{k} \cdot \operatorname{GIVE} k m n\right)$, correctly allowing the pronoun him to access its antecedent, the cyclist, since it is introduced into the discourse context by A CYCLIST and passed, via AND, to the content containing HIM. In contrast to (49), the verb phrase content in (51) is the second argument to the comma intonation, while the apposition is the last argument. I assume that this argument order results from the utterance-final syntactic configuration of the supplement in (50), but I leave the syntax of supplement constructions outside the scope of this paper (see Martin 2015 for an account of the syntax of both medial and final supplements).

This account can also handle anaphora both out of and into a supplement simultaneously.

(52) Melanie $_{i}$, who bought herself $i$ an Italian car , drives it $_{j}$ every day.

This example gets the semantics below, where HERSELF is defined similarly to SHE in (A.23), IT as in (A.25), and CAR and DRIVE are generated by dyn :

(COMMA MELANIE $\left(\mathrm{WHO}_{\mathrm{nrrc}} \lambda_{n} \cdot \mathrm{HERSELF}_{i} \cdot(\mathrm{A} \text { CAR })_{m} \cdot \mathrm{BUY} m\right.$ i $\left.n\right)$

$$
\begin{aligned}
& \left.\lambda_{n} \cdot \operatorname{IT}_{m} \cdot \operatorname{DRIVE} n\right) \\
= & \left(\operatorname{MELANIE}_{n} \cdot \operatorname{HERSELF}_{i} \cdot(\mathrm{A} \mathrm{CAR})_{m} \cdot \mathrm{BUY} m \text { i } n\right) \text { AND } \\
& \left(\operatorname{THE} \lambda_{n} \cdot\left(\operatorname{HERSELF}_{i} \cdot(\mathrm{A} \text { CAR })_{m} \cdot \mathrm{BUY} m \text { i } n\right) \lambda_{n} \cdot \operatorname{IT}_{m} \cdot \operatorname{DRIVE} m n\right)
\end{aligned}
$$

As the reduction shows, the reflexive pronoun herself is able to access Melanie as its antecedent. Also, the indefinite a car in the supplement introduces 
Supplemental update

a discourse referent which is then made available, via AND, to the second conjunct, where the pronoun it can take it as antecedent.

Finally, example

(53) Melanie, who adores an $\operatorname{Italian}_{i}$, met some cyclist, his ${ }_{i}$ best friend.

provides an instance of anaphora between two supplements. The treatment given to (53) too is straightforward (as before, FRIEND is generated by $\mathrm{dyn}_{1}$ ).

(COMMA MELANIE $\left(\mathrm{WHO}_{\text {nrrc }} \lambda_{n} \text {.(A ITALIAN }\right)_{m}$.ADORE $m n$ )

$\lambda_{n} \cdot\left(\right.$ COMMA (A CYCLIST) $\lambda_{k} \cdot($ MEET $k n)($ PRED HIS FRIEND $\left.)\right)$

$=$ MELANIE $_{n} \cdot\left(\left(\right.\right.$ A ITALIAN $_{m} \cdot$ ADORE $\left._{m} n\right)$ AND

THE $\lambda_{n}$. (A ITALIAN $)_{m} \cdot($ ADORE $m n) \lambda_{n} \cdot\left(\left((\text { A CYCLIST })_{k}\right.\right.$.MEET $\left.k n\right)$ AND

THE $\lambda_{k} \cdot(\operatorname{MEET} k n)$ (PRED HIS FRIEND))

Here I assume that binding constraints intervene to ensure that HIS (defined in (A.26)) cannot take the cyclist as its antecedent, so that HIS must instead select the Italian, as desired. Proffering this reading is equivalent to the sequence of proposals Melanie adores an Italian $_{j}$. She $e_{i}$ met some cyclist . The cyclist she $_{i}$ met $_{k}$ is his ${ }_{j}$ best friend.

One of the reviewers noticed that the incremental interpretation imposed by this dynamic system may cause problems for certain examples of anaphora with supplements, such as

(54) After the big thunderstorm, some cyclist, whose bike was destroyed by it, managed to finish the tour.

The potential problem with this example, in the current account, is that the indefinite some cyclist scopes widest in the projective reading, which means that the pronoun it needs to precede its antecedent the big thunderstorm. However, I note that this is part of a more general problem for accounts of anaphora in dynamic systems. The system proposed here, and many other dynamic semantics, needs to say something special about how the anaphoric link in the following example is established:

(55) After she ${ }_{i}$ got a bike, a friend of mine ${ }_{i}$ was finally able to go on rides in the mountains.

Since anaphora functions no differently for the case of supplements in this account, a solution to the cataphora in (55) would immediately handle (54) too. The same reviewer also points out that this problem is not limited to definite anaphora, citing the following: 
(56) a. The Tour was won by a Texan, who then never participated in another Tour.

b. The Tour was won by a Texan, who won the Tour again the next year.

I take these to be instances of the same problem as cataphora, namely that anaphoric elements sometimes need to select antecedents from later contexts, that is, antecedents that are not present in the input context. As for (54), an extension of this account that handles cataphora should also be capable of handling (56).

\subsection{Supplement scope and projection}

In this section, I examine the predictions this account makes for the interactions between supplements and semantic operators.

\subsubsection{Negation}

One of the main challenges posed to an account of supplements by examples like

(19a) It's not true that Lance, a doper, won the Tour de France.

is setting things up so that the information that Lance is a doper projects, escaping the effects of negation, while the information that he won does not. With dynamic negation defined in (A.6), we get the following analyses for (19a):

NOT (COMMA LANCE (PRED A DOPER) WIN-TDF)

$$
\text { (COMMA LANCE (PRED A DOPER) }{ }_{n} \text {.NOT (WIN-TDF } n \text { ) }
$$

The semantics of (57) reduces to

$$
\text { NOT ((LANCE (PRED A DOPER)) AND THE (PRED A DOPER) WIN-TDF), }
$$

with both the supplement and main clause content negated. But since (58) reduces to

$($ LANCE (PRED A DOPER) $)$ AND (THE (PRED A DOPER) $)_{n}$.NOT (WIN-TDF $\left.n\right)$, only the information that Lance won the Tour ends up in the scope of negation. This means that when (58) is proffered via cc, the apposition signaling 
Supplemental update

that Lance is a doper is separated off into its own proposal, capable of updating the discourse context untouched by negation. Under the supplement-wide reading (58), proposing (19a) is equivalent to proposing Lance is a doper. He didn't win the Tour de France by Theorem A.2.

As (58) shows, this account captures the observation that a widest-scope supplement escapes the effects of negation. But crucially, the comma intonation itself is not empowered with the ability to force the supplement to project - the negation-wide and supplement-wide readings are equally possible for (19a). As discussed in Section 2.1.1, the preference for negation to target only the verb phrase content derives from an independent source, which in the case of (19a) is the preference for proper names to scope wide, favoring (58) over (57). Since supplements piggyback onto their anchors, the apparent projection of the supplement in (19a) arises as a secondary effect of this wide-scope preference. So in this model, supplements are not inherently projective. Instead, their projection arises based on how the comma intonation interacts with certain external conditions.

Negation can, of course, also interact with supplements with anchors that are not proper names, as in

(19b) It's not true that some cyclist, a doper, won the Tour de France.

Examples like (19b), in contrast to (19a), are truly ambiguous between the reading where negation takes widest scope and the one where the supplement does, as discussed in Section 2.1.2. Accordingly, this semantics predicts two possible readings for (19b), just as it does for (19a). The two readings generated for (19b) are the following:

NOT (COMMA (A CYCLIST) (PRED A DOPER) WIN-TDF)

$(\text { COMMA (A CYCLIST) }(\text { PRED A DOPER }))_{n}$.NOT (WIN-TDF $\left.n\right)$

For (59), both the indefinite, which introduces the cyclist discourse referent, and the apposition anchored to it are caught up in the negation's scope. However, the inverse scope reading (6o), where the supplement is wider, reduces to

$$
\text { (A CYCLIST (PRED A DOPER)) AND (THE (PRED A DOPER) })_{n} \cdot \operatorname{NOT}(\text { WIN-TDF } \boldsymbol{n}) \text {. }
$$

Note the similarity between this semantics and the one above for the preferred reading of (19a) in (58): under proffering, cc separates the information that the newly-introduced cyclist is a doper from the information that the doping cyclist didn't win the Tour de France, that is, the supplement projects. 
But here again, the semantics of the comma intonation does nothing to favor one of these readings over the other - the independent preference for surface scope intervenes to favor the negation-wide reading (59) in this case.

\subsubsection{Quantification}

As illustrated in (24) and (25), true GQs like every $D$ and no $D$ cannot under normal circumstances serve as the anchors to supplements (though some exceptions are discussed in Section 3.4.3, below). As defined, this account's model of the comma intonation gives a straightforward story about why quantificational anchors are normally problematic. The anchor in

(61) \#Every cyclist, a doper, won the Tour de France.

is ruled out in this account by a familiar mechanism: the limitations on the accessibility of discourse referents introduced in the scope of negation, a quantifier, or a conditional.

To illustrate, note that the meaning corresponding to (61) is

$$
\text { COMMA (EVERY CYCLIST) (PRED A DOPER) WIN-TDF , }
$$

where the dynamic determiner meaning EVERY is as defined in (A.15). This semantics reduces as follows:

(EVERY CYCLIST (PRED A DOPER)) AND THE (PRED A DOPER) WIN-TDF

This reduction shows clearly why (61) is infelicitous. The cyclist discourse referent is introduced in the scope of EVERY, and therefore has its lifespan limited to that scope. As a result, the anaphoric quantifier THE (PRED A DOPER) is unable to select this doping cyclist referent as its antecedent, and since no other suitable antecedent is available, infelicity results. ${ }^{7}$ This is because proffering (61) is equivalent, by Theorem A.2, to what would be generated for the infelicitous two-utterance discourse Every cyclist is a doper. \# The doper won the Tour de France. This mechanism applies to all quantificational anchors, with the same effect arising for no, not every, each, (not) all, and any other quantifier or connective defined in terms of dynamic negation, such as implication (see Definition A.14).

The interaction between supplements and true quantifiers that occur elsewhere than as their anchors is very similar to their interaction with negation. Take the following example, a slight variant of (10):

7 As for how it is that other potential antecedents get ruled out, I discuss this below, in Section 3.4.3, in connection with exceptional discourse anaphoric effects. 
Supplemental update

(62) Every boxer has a coach, who is famous.

In this example, as discussed above in Section 2.1, we get both the reading in which each boxer has a potentially different famous coach and the one where there is a single famous coach for all boxers. After using dyn to define the necessary dynamic properties, we can derive both of the dynamic meanings for (62) below.

$(\text { EVERY BOXER })_{n} \cdot($ COMMA (A COACH $)$

$$
\left.\lambda_{m} \cdot(\text { HAVE } m n)\left(\text { WHO }_{\text {nrrc }} \text { IS }_{\text {pred }} \text { FAMOUS }\right)\right)
$$

(64) (COMMA (A COACH)

$$
\left.\lambda_{m \cdot}(\text { EVERY BOXER })_{n} \cdot(\text { HAVE } m n)\left(\text { WHO }_{\text {nrrc }} \text { IS }_{\text {pred }} \text { FAMOUS }\right)\right)
$$

The supplement-narrow semantics in (63) reduces to

$(\text { EVERY BOXER })_{n} \cdot\left(\left((\text { A COACH })_{m} \cdot\right.\right.$ HAVE $\left.m n\right)$ AND

THE $\lambda_{m}$. (HAVE $m n$ ) FAMOUS) .

As desired, this is the reading where for each boxer, there is a different famous coach. On the other hand, the supplement-wide interpretation in (64) reduces to

$$
\begin{aligned}
& \left((\text { A COACH })_{m} \cdot(\text { EVERY BOXER })_{n} \cdot \text { HAVE } m n\right) \text { AND } \\
& \text { THE } \lambda_{m} \cdot\left((\text { EVERY BOXER })_{n} \cdot \operatorname{HAVE~} m n\right) \text { FAMOUS }
\end{aligned}
$$

which correctly gives the truth conditions that there is some famous individual who coaches every boxer.

For (62), surface scope is preferable as it is more generally, making (63) the preferred reading. However, as discussed above in Section 2.1.1, other factors can come into play to force one reading to the exclusion of others. One example is

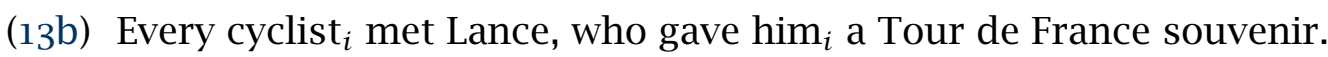

The reading of (13b) signaled by the subscripted indices is only available if the quantifier Every cyclist outscopes the supplement. One semantics that this account generates for $(13 b)$ is

(65) COMMA LANCE $\lambda_{m}$. (EVERY CYCLIST $)_{n} \cdot(\operatorname{MEET} m n)$

$$
\left.\left(\text { WHO }_{\text {nrrc }} \lambda_{m} \cdot \text { HIM }_{n} \text {. (A SOUVENIR }\right)_{k} \text {.GIVE } k n m\right) \text {, }
$$


Scott Martin

which reduces to

$$
\begin{aligned}
& \left(\operatorname{LANCE}_{m} \cdot\left(\text { EVERY CYCLIST }_{n} \cdot \operatorname{MEET} m \boldsymbol{m}\right)\right. \text { AND } \\
& \text { THE } \lambda_{m} \cdot\left((\text { EVERY CYCLIST })_{n} \cdot \operatorname{MEET} m n\right) \\
& \lambda_{m} \cdot \mathrm{HIM}_{n} \text {.(A SOUVENIR) } k \cdot \text { GIVE } k n m \text {. }
\end{aligned}
$$

However, this reading is infelicitous, since the pronoun HIM does not occur in the scope of EVERY CYCLIST, and therefore cannot access the discourse referent it introduces. Also, its corresponding truth conditions do not line up with intuitions, since (65) requires Lance to give every cyclist the same souvenir. In the other reading, by contrast, HIM does occur in EVERY CYCLIST'S scope:

$$
\begin{aligned}
& (\text { EVERY CYCLIST })_{n} \cdot\left(\text { COMMA LANCE } \lambda_{m} \cdot(\operatorname{MEET} m n)\right. \\
& \left.\left(\text { WHO }_{\text {nrc }} \lambda_{m} \cdot \mathrm{HIM}_{n} \cdot(\text { A SOUVENIR })_{k} \text {.GIVE } k n m\right)\right) \\
& =\left(\text { EVERY CYCLIST } _ { n } \cdot \left(\left(\text { LANCE }_{m} \cdot \text { MEET } m n\right)\right.\right. \text { AND } \\
& \text { THE } \left.\lambda_{m} \cdot(\operatorname{MEET} m n) \lambda_{m} \cdot \operatorname{HIM}_{n} \cdot(\text { A SOUVENIR })_{k} \cdot \operatorname{GIVE} k n m\right)
\end{aligned}
$$

And so, as desired, discourse anaphora forces the reading for (13b) in (66), in which Every scopes wide. Note that this reading is also preferable at the level of truth conditions, since it is possible that each cyclist received a different souvenir from Lance. This way of blocking certain scopings could provide a similar treatment of examples like (12a) by extending the account so that events also introduce discourse referents, but I do not pursue such an extension here.

In some cases, the predicted scope ambiguity is spurious at the truthconditional level, but important for determining projection, as in the following slight simplification of (13c):

(67) Every cyclist met Lance, a doper.

For this example, we get both of the following readings:

$$
\left(\text { COMMA LANCE } \lambda_{m} \cdot(\text { EVERY CYCLIST })_{n} \cdot(\text { MEET } m n)(\text { PRED A DOPER })\right)
$$

$$
(\text { EVERY CYCLIST })_{n} \cdot\left(\text { COMMA LANCE } \lambda_{m} \cdot(\operatorname{MEET} m n)(\text { PRED A DOPER })\right)
$$

Although no discourse anaphoric effects are involved, only (68) is the projective reading, which reduces to

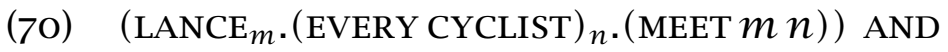

$$
\left.\left(\text { THE } \lambda_{m} \cdot(\text { EVERY CYCLIST })_{n} \cdot(\text { MEET } m n) \text { (PRED A DOPER }\right)\right) \text {. }
$$

When this reading is proffered, cc splits the proposal that Lance dopes off on its own. Again by Theorem A.2, this projection arises because proffering 
Supplemental update

(68) is equivalent to the sequence of proposals Every cyclist met Lance. The person every cyclist met is a doper. Proffering (69), on the other hand, yields only a single proposal with all of its information in the scope of Every cyclist. In a parallel with the negation example (19a), the default preference for the projective reading (68) of (67) derives from a more general tendency for proper names to take widest scope.

\subsubsection{Supplement telescoping}

What about those Tibetan Buddhists? As discussed above in Section 2.1.3, there is a reading of (27) under which the Dalai Lama is interpreted to be the spiritual mentor of every Tibetan Buddhist, that is, the supplement can project.

(27) No Tibetan Buddhist ${ }_{i}$ thinks the Dalai Lama, his ${ }_{i}$ spiritual mentor, would ever cave to Chinese pressure tactics.

Since the singular pronoun his in (27) is bound by the quantifier No Tibetan Buddhist, this projective reading needs to be squared with cases where discourse anaphora forces the supplement-narrow reading, such as (13b).

As a preliminary to examining the possible readings generated for (27), the dynamic meaning of the sentential complement verb thinks is THINK : $\mathrm{k} \rightarrow \mathrm{d}_{1}$, defined as

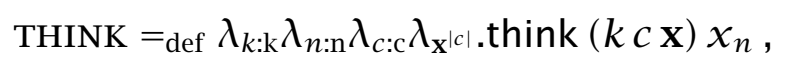

where think $: \mathrm{p} \rightarrow \mathrm{p}_{1}$ is the static analog. For example, assuming a model of pleonastic it, which I do not discuss here, this translation lets us derive the following dynamic meaning of Kim thinks it's raining:

$$
\operatorname{KIM}(\text { THINK RAIN })=\lambda_{c: c} \lambda_{\mathbf{x}^{|c|}} .(\text { think rain }) x_{(\text {the NAMED-KIM } c)}
$$

The relevant semantics for No, the, and his are given in (A.14), (A.18), and (A.26), respectively; dyn gives the dynamic properties required to model (27).

With these extensions in place, we get the following reading for (27), where T-B and D-L respectively abbreviate the dynamic properties TIBETANBUDDHIST and DALAI-LAMA, and CAVE abbreviates the denotation of the verb phrase would ever cave to Chinese pressure tactics:

(71) COMMA $($ THE D-L $)($ PRED HIS MENTOR $) \lambda_{m} \cdot(\text { NO T-B })_{n} \cdot$ THINK $($ CAVE $m) n$
$=($ THE D-L $($ PRED HIS MENTOR $))$ AND
$\quad(\text { THE }(\text { PRED HIS MENTOR }))_{m} \cdot(\text { NO T-B })_{n} \cdot$ THINK $($ CAVE $m) n$ 
This reading, which is preferred because the definite the Dalai Lama scopes widest, almost gives the projective reading of (27), the one where the Dalai Lama is every Tibetan Buddhist's mentor. In addition to requiring cataphora, the pronoun HIS in the first conjunct is prevented from accessing the Buddhist referent because the scope of NO, by virtue of being defined in terms of NOT, limits the accessibility of that referent.

Note that, by Theorem A.2, proffering (71) gives a proposal equivalent to the sequence of proposals in

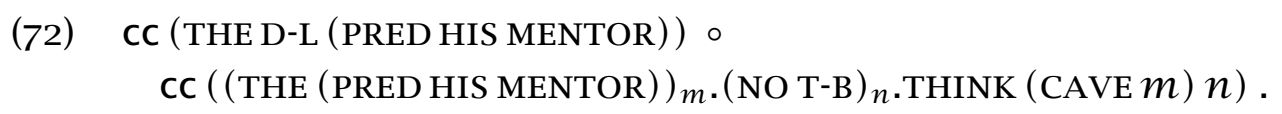

This shows that (27) can be treated similarly, in this account, to instances of telescoping like (34), repeated from above.

(34) Each degree candidate e $_{i}$ walked to the stage. $\mathrm{He}_{i}$ took his ${ }_{i}$ diploma from the dean and returned to his seat. $_{i}$ se

In (34), the first utterance introduces a discourse referent for the degree candidate whose lifespan is normally limited to the scope of Each, but the pronouns in the second utterance are able to select it as their antecedent without problem. The situation is similar in the semantics for (27) in (72): the second proposal contains a discourse referent for a Buddhist whose scope is limited by NO, but this discourse referent needs to be accessed by HIS in the first proposal.

An account of telescoping is sketched by Roberts (2005), who explains the difference both between (27) and (73) and between (34) and (74) in terms of the genericity of the information predicated of the pronouns.

(73) No Tibetan Buddhist ${ }_{i}$ thinks the Dalai Lama, \# his ${ }_{i}$ old friend from school, would ever cave to Chinese pressure tactics.

(Craige Roberts, personal communication)

(74) Each degree candidate en $_{i}$ walked to the stage. \# $\mathrm{He}_{i}$ had a degree in astrophysics.

For Roberts, the decreased acceptability of (73) in comparison to (27) is based on the fact that the supplement his spiritual mentor from the felicitous (27) is interpreted as applying to any Tibetan Buddhist, whereas his old friend from school is interpreted as applying to only a single, particular Buddhist. Thus the noun phrase No Tibetan Buddhist can serve as what Roberts calls a "licensing NP" under certain tightly constrained generic interpretations, but this effect 
Supplemental update

is otherwise ruled out. Example (74) is similar: it cannot be interpreted as implying that every degree candidate had a degree in astrophysics, in contrast to (34), where returning to his seat seems to more naturally apply to all of the candidates. An example of telescoping that more closely parallels (27) is

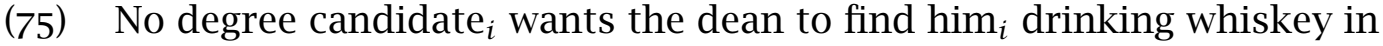
the dorm. His ${ }_{i}$ parents would be very upset.

Here, the quantifier No degree candidate would normally limit the accessibility of its corresponding discourse referent, but the pronoun His is able to access it.

Roberts's approach could be adapted to handle cases like (27), as could Wang, E. McCready \& Asher's (2006) formal approach to loosening up the usual accessibility constraints imposed by true quantifiers. For Wang, E. McCready \& Asher, instances of telescoping are licensed as long as certain conditions apply, which are encoded in terms of discourse relations. Based on a survey of native speakers, Wang, E. McCready \& Asher conclude that the difference between (34) and (74) is that different discourse relations are in effect, only one of which allows for telescoping. A similar appeal could be made to explain the difference between examples like (27) and (73). Like Roberts's telescoping, this approach could also be implemented in the current framework by adding discourse relations and enhancing discourse contexts with more structure, following Wang, E. McCready \& Asher and Asher \& Pogodalla (2011), but I do not pursue it here.

We might want to argue that the divergent felicity of (27) and (73) is simply due to the knowledge that the Dalai Lama is every Tibetan Buddhist's spiritual mentor. But no such argument is available for (29), since there is no background assumption that the Wall Street Journal is naturally the preferred newspaper of every business owner I know. Similarly to (73), an infelicitous variant of (29) can be constructed by switching out the appositive which is naturally his favorite newspaper with content less amenable to a generic construal.

(29) Every business owner I know ${ }_{i}$ wants the Wall Street Journal ${ }_{j}$, which is naturally his $_{i}$ favorite newspaper, to expand its ${ }_{j}$ editorial page.

(76) Every business owner ${ }_{i}$ wants the Wall Street Journal, \# which he ${ }_{i}$ had a subscription to when he lived in the U.S. back in the 1980's, to expand its editorial page. 
The infelicitous NRRC in (76) is deliberately chosen because it is difficult to construe as generically applying to all business owners, and it is impossible to attribute its projection to background knowledge about business owners that applies outside the scope of Every.

I briefly note that this excursion into telescoping helps sharpen the proposed account's predictions for supplements.

(77) Some cyclist is a doper. \# Every cyclist, a doper, won the Tour de France.

Assuming that both utterances are proffered in sequence, the current account generates the two-utterance discourse

$$
\begin{aligned}
& \text { CC (A CYCLIST } \left.\left(\text { IS }_{\text {pred }}(\text { PRED A DOPER })\right)\right) \circ \\
& \text { CC (COMMA (EVERY CYCLIST) (PRED A DOPER) WIN-TDF })
\end{aligned}
$$

for (77). If telescoping were always impossible, our analysis would allow the doper mentioned in the second proposal to be anteceded by the cyclist introduced in the first! This is because the second utterance's content reduces to

(EVERY CYCLIST (PRED A DOPER) ) AND THE (PRED A DOPER) WIN-TDF .

Here, the doping cyclist discourse referent would normally have its lifespan limited by EVERY, and therefore, the instance of THE would pick up the doping cyclist referent introduced by Some cyclist. But under an analysis following Roberts or Wang, E. McCready \& Asher, the most salient doping cyclist referent is the one in the scope of EVERY, and this referent's potential to antecede the subsequent anaphora is ruled out because the right conditions are not present to license it for exceptional binding, giving rise to infelicity, as desired. Note that this is part of a more general pattern, as it is exactly the same mechanism that rules out examples of quantified supplements like (61) in Wang, E. McCready \& Asher's analysis. Similarly, in Roberts's (2005) explanation, the noun phrase Every cyclist in (77), though most salient, fails to license telescoping due to lack of genericity - despite recent scandals, not every cyclist can be assumed to be a doper. And because antecedents for anaphora must be maximally salient, the discourse referent introduced in the first utterance is not a suitable antecedent.

\subsubsection{Gradient deniability and salience}

As discussed in Section 3.2.2, proffering 
Supplemental update

(1a) Some cyclist, a doper, won the Tour de France

gives rise to a separate, more recent, proposal in addition to the one corresponding to the supplement - namely, the proposal that the doping cyclist won the Tour. This effect arises due to the interaction between the comma intonation and the process of proffering content, which turns a denotation into a proposal: by Theorem A.2, proffering (1a) is equivalent to the sequence of proposals

(46) CC (A CYCLIST (PRED A DOPER)) ○ CC (THE (PRED A DOPER) WIN-TDF) .

The first proposal contains the information that some cyclist is a doper, and the second that the doping cyclist just mentioned won the Tour.

In this account, following AnderBois, Brasoveanu \& Henderson (2010, 2015), Ginzburg (2012), Koev (2012), and Schlenker (2013b), a proposal's recency figures into its susceptibility to direct denial (cf. (40)). This prediction matches the observation that the supplement in (1a) is harder to challenge directly than the main clause content. There is therefore a parallel, in the current account, between the mechanism of denial in discourse and the relative salience of antecedents for definite anaphora: recency is a major, although not the only, criterion in determining a proposal's salience. For (1a), other things being equal, a direct denial would more easily target the more salient proposal that the doping cyclist won. Amaral, Roberts \& Smith (2007) and Koev (2012) argue that this salience-based deniability is a strong constraint on the range of possible interpretations, making the main clause content the only deniable proposal for (1a). But based on the evidence provided by AnderBois, Brasoveanu \& Henderson (2010) and Schlenker (2013b), I construe the correlation between a proposal's recency and its deniability as a weaker constraint that can be overridden under certain conditions, as in the possible denials of (39).

The interaction between the comma intonation and supplement scope preferences has implications for supplement deniability as well. For example, due to the preference for Lance to scope wide in

(67) Every cyclist met Lance, a doper,

the reading (70), a reduction of (68), is favored over (78), a reduction of (69).

(7O) $\quad\left(\right.$ LANCE $_{m} \cdot\left(\right.$ EVERY CYCLIST $\left._{n} \cdot \operatorname{MEET} m \boldsymbol{n}\right)$ AND THE $\lambda_{m} \cdot\left((\text { EVERY CYCLIST })_{n}\right.$.MEET $\left.m n\right)$ (PRED A DOPER)

(78) (EVERY CYCLIST $)_{n} \cdot\left(\left(\right.\right.$ LANCE $\left._{m} \cdot \operatorname{MEET} m n\right)$ AND THE $\lambda_{m} \cdot(\operatorname{MEET} m n)($ PRED A DOPER) 
The relative favorability of (70) implies that the supplement preferentially projects, and therefore that two proposals result from proffering (67) by Theorem A.2: the first contributes the information that every cyclist met Lance, and the second the information that he is a doper. This seems to be the correct prediction, since the proposal corresponding to (70) allows the supplement's content to be challenged in isolation.

The comma intonation's interaction with other scope preferences can also impact a supplement's deniability, as in

(62) Every boxer has a coach, who is famous.

Taking the surface scope reading

$$
\begin{aligned}
& (\text { EVERY BOXER })_{n} \cdot(\text { COMMA (A COACH }) \\
& \left.\left.\lambda_{m} \text {. (HAVE } m n\right)\left(\text { WHO }_{\text {nrrc }} \text { IS }_{\text {pred }} \text { FAMOUS }\right)\right) \text {, }
\end{aligned}
$$

which is preferred as surface scope is generally, this account immediately predicts that the following denial is possible:

(79) No, that's not true. Not every boxer has a famous coach.

Here, the entirety of (63) is being rejected. The inverse scope reading (64), by contrast, yields the following sequence of proposals when proffered:

$$
\begin{aligned}
& \text { cC }\left((\text { A COACH })_{m} \cdot(\text { EVERY BOXER })_{n} \cdot \text { HAVE } m n\right) \circ \\
& \quad \text { cC }\left(\operatorname{THE} \lambda_{m} \cdot(\text { EVERY BOXER })_{n} \cdot(\text { HAVE } m n) \text { FAMOUS }\right)
\end{aligned}
$$

With less salient proposals still being deniable, although with more effort, we get the prediction that the following denials of (80) can be felicitously issued.

(81) No, that's not true.

a. Their coach isn't famous.

b. He doesn't coach every boxer.

c. That coach doesn't coach every boxer, and she isn't famous either.

The denial in (81a) targets the more recent proposal in (80), while the one in (81b) targets the first proposal. And it seems that the denial in (81c), which targets the conjunction of both proposals, is also possible.

Does this mean that the semantics in (63) is too constrained? Could the following denial be used as a follow-up to it?

(82) No, that's not true. Not every boxer has a coach. 
Supplemental update

Noting that (63) is truth-conditionally equivalent to

$$
\begin{aligned}
& \left((\text { EVERY BOXER })_{n} \cdot(\text { A COACH })_{m} \cdot \operatorname{HAVE} m n\right) \text { AND } \\
& (\text { EVERY BOXER })_{n} \cdot \operatorname{THE} \lambda_{m} \cdot(\text { HAVE } m n) \text { FAMOUS }
\end{aligned}
$$

proffering (63) corresponds to a sequence of two proposals, again by Theorem A.2: the information that each boxer has a coach, followed by the information that the coach every boxer has is famous. So the denial in (82) is at least possible for (63), although it needs to target the less recent, and therefore less salient, proposal. The denials in (79) and (81a) are possible as well, targeting the second proposal. The ones in (81b) and (81c), on the other hand, only seem appropriate for use with the inverse scope reading (64), as both implicate that a single coach is being discussed through the use of the definites He, That coach, and she.

Similar effects can be seen for examples like

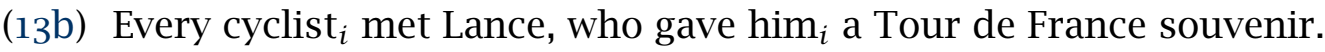

As discussed above in Section 3.4.2, the reading for (13b) with Every cyclist wide is forced by the bound variable. The available interpretation is

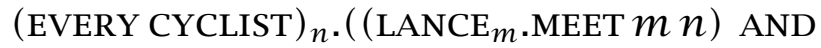
THE $\lambda_{m} \cdot(\operatorname{MEET} m n) \lambda_{m} \cdot \operatorname{HIM}_{n}$.(A SOUVENIR $)_{k} \cdot$ GIVE $\left.k n m\right)$,

because the pronoun has to be able to select the quantified-over cyclist as its antecedent. But this semantics is equivalent to

$$
\begin{aligned}
& \left(\left(\text { EVERY CYCLIST }_{n} \cdot \text { LANCE }_{m} \cdot \operatorname{MEET} m \boldsymbol{n}\right)\right. \text { AND } \\
& \left.(\text { EVERY CYCLIST })_{n} \text {.THE } \lambda_{m} \text {. (MEET } m n\right) \\
& \lambda_{m} \cdot \text { HIM }_{n} \text {. (A SOUVENIR) } k \text {.GIVE } k n m \text {, }
\end{aligned}
$$

which in turn corresponds, under proffering, to the sequence of proposals consisting first of the information that every cyclist met Lance and second that Lance gave each of them a souvenir. Given this equivalence, this account predicts that all of the following denials are can be issued to (13b):

(83) No, that's not true.

a. Every cyclist didn't meet Lance/Not every cyclist met Lance.

b. Lance didn't give every cyclist he met a souvenir.

c. Every cyclist didn't meet Lance, and anyway he didn't give them all souvenirs. 
These denials all seem plausible. But as for whether they are actually attestable, my own intuitions about their status, along with the intuitions of many native English speakers I have talked to about them, are not clear.

More empirical investigation would be required to determine which denials can be felicitously used with which proposal sequences. The position of the semantic account given here is that any proposal in a sequence can be felicitously targeted for denial, with more recent proposals being more easily targetable due to salience effects. Locutions like Hey, wait a minute! are not always required to target a less recent proposal, in contrast to Amaral, Roberts \& Smith 2007 and Koev 2012. In this way, the account is sympathetic to the view presented by Schlenker (2013b) of supplement deniability being a gradient effect. However, this account does not provide a formal implementation of salience in the semantics because it involves so many factors besides recency: the discourse context, world knowledge, default assumptions, syntactic features, etc. It also seems likely that more general discourse processes partly influence which proposals can be easily targeted for denial, such as the notions of relevance to a QUD developed by Simons et al. (2010) and Ginzburg (2012).

\section{Summary and comparison with previous accounts}

To sum up, a supplement is formed by an apposition attaching to an anchoring GQ, so that the supplement's scope is exactly that of the anchor. Supplements can, as a result, be interpreted in the scope of semantic operators.

Projection arises when a supplement's anchor takes widest scope, generating separate at-issue proposals for both the supplement and main clause content. When no embedding operators are present, widest scope is the only one available, and so supplements always project when unembedded. On the other hand, when a supplement cooccurs with scope-taking operators, the factors that determine whether it projects are derived from more general processes that apply to its anchor, such as discourse anaphora and quantifier scope preferences. That is, projection is not an inherent property of supplements but a secondary effect of the scope of their anchors. This account remains neutral on how other factors, such as the discourse context, the QUD, default assumptions, and world knowledge, influence supplement scope possibilities. 
Supplemental update

Finally, since a widest-scope supplement generates an at-issue proposal, it can be challenged. However, a more salient main-clause proposal may interfere with its deniability by being more recent, as in the case of a supplement occurring in utterance-medial position.

The definition of the comma intonation in (A.27) hybridizes two competing ways of modeling supplements in the literature: as predicates on the anchor (Potts 2005) versus as free-standing propositions with an anaphoric argument (del Gobbo 2007, Nouwen 2007), although (A.27) employs ordinary discourse anaphora rather than making recourse to E-type pronouns, as does del Gobbo. Apart from this resemblance, this account is quite different from Potts's and other multidimensional accounts (Nouwen 2007, Barker, Bernardi \& Shan 2010, E. S. McCready 2010, Giorgolo \& Asudeh 2012, Kierstead \& Martin 2012, Martin 2013), chiefly because they do not allow supplements to interact with other operators. In some of these accounts, the extra meaning dimension is also aimed at analyzing the expressives discussed by Potts (2005), but I interpret the scope-taking capability of supplements as evidence against Potts's contention that supplements and expressives belong in the same natural class. The approach presented here also differs significantly from the unidimensional accounts due to Kubota \& Uegaki (2009), AnderBois, Brasoveanu \& Henderson (2010, 2015), Koev (2012, 2014) and Murray (2014) for the same reason, namely that they do not countenance a notion of supplement scope. Additionally, only some of these previous accounts (Giorgolo \& Asudeh 2012, Martin 2013, Koev 2014, Murray 2014, AnderBois, Brasoveanu \& Henderson 2015) give an explicit model of how supplements participate in anaphoric interactions.

A somewhat similar account is given by Schlenker (2010, 2013b), who models supplements as interacting with scope-taking operators in a unidimensional setting, building on work by del Gobbo (2007). However, it is hard to say how Schlenker's account could be made to allow for anaphora. Also, as discussed in Section 2.1.1, there is reason to doubt Schlenker's principle of Translucency as an explanation for supplement projection. And as Schlenker (2013b: 20) himself notes, his account's model of supplements as attaching themselves to fully-formed propositions and parasitically "stealing" a "referential index" from them constitutes a departure from compositionality in the strict sense, since it requires a supplement's denotation to be partially determined by an adjacent constituent's interpretation.

The account that is probably most similar to this one is due to AnderBois, Brasoveanu \& Henderson (2015), who model supplements unidimensionally, 
allowing anaphoric interactions with surrounding content and even capturing some cases where a supplement fails to project. But as discussed in Section 2.1.2, this account differs from AnderBois, Brasoveanu \& Henderson's at the empirical level, since it allows supplements generally to participate in scope interactions. For AnderBois, Brasoveanu \& Henderson, only one-asides like (15) can have a nonprojective (i.e., narrow scope) reading - all other supplements must project. Through the data and arguments in Section 2.1.2, I hope to have shown convincingly that the ability of supplements to scope narrow is not limited to one-asides, and therefore that AnderBois, Brasoveanu \& Henderson's requirement that supplements always scope widest is too restrictive.

The divergence in predictions between AnderBois, Brasoveanu \& Henderson's account and this one, which I argue is more empirically adequate, comes down to the following fundamental conceptual difference: for AnderBois, Brasoveanu \& Henderson, a supplement intervenes upon its anchor to force widest scope; the account presented here inverts this relationship, so that a supplement's scope is determined by its anchor's scope. The AnderBois, Brasoveanu \& Henderson account's inability to correctly model supplements in narrow-scope position stems from its prohibition on the interaction between supplements and scope-taking operators. By contrast, this account is able to ascribe both supplement projection and scope to independent mechanisms such as discourse anaphora and quantifier scope preferences.

There is also cause to question AnderBois, Brasoveanu \& Henderson's generalization that certain supplements, such the NRRC in (84b), cannot interact with the QUD by virtue of not being at-issue.

(84) Context: The interlocutors are participants at a math conference.

a. Do you know whether the axiom of Choice is independent of ZF?

b. Well, Paul Cohen, who proved it is back in 1963, is sitting in the back row. So you can go ask him.

(Adapted from Pollard \& Smith 2011)

In (84b), the NRRC who proved it is back in 1963 directly addresses the question raised in (84a). This account takes a different strategy from AnderBois, Brasoveanu \& Henderson, casting supplements as at-issue denotations that interact scopally with surrounding content as well as being subject to denial, without taking a stand on exactly how they interact with the QUD. That is, supplement projection and at-issueness are dissociated, in contrast to 
Supplemental update

AnderBois, Brasoveanu \& Henderson, since supplements are always at-issue and projection is a mere epiphenomenon of scope.

The account itself is expressed in a compositional dynamic semantics that is designed for general semantic analysis, being separately capable of modeling all the usual dynamic phenomena (multi-utterance discourses, anaphoric links across arbitrary stretches of discourse, donkey anaphora, etc.) using familiar methods, such as a mainstream model of noun phrases as generalized quantifiers. The extra semantic dimensions posited in other accounts are supplanted by imbuing widest-scope supplements with the potential to generate separate proposals. In addition to having only a single meaning dimension, this account does not invoke any rules that are specially tailored to the case of supplements, such as Potts's (2005: 68) "parsetree interpretation", different modes of combination for supplement content, an application of the continuation passing technique (cf. Kubota \& Uegaki 2009, Barker, Bernardi \& Shan 2010), or the use of monads (Giorgolo \& Asudeh 2012). In fact, this account is quite parsimonious because the only special-purpose machinery it requires is the dynamic meaning of the comma intonation given in (A.27).

\section{Conclusion}

A closer look at the data pertaining to supplements, much of it undertaken in recent work by Amaral, Roberts \& Smith (2007), AnderBois, Brasoveanu \& Henderson (2010, 2015), Koev (2012, 2014), Martin (2013), Nouwen (2014) and Schlenker (2010, 2013a, 2013b), calls into question some central aspects of Potts's (2005: 42) characterization of them. They are not scopeless, as they clearly interact with semantic operators, and anaphoric links between supplements and surrounding material are unproblematic. Moreover, it is not strictly forbidden for supplements to be directly denied, although some extra effort may be required when they occur in nonfinal position. These facts cast considerable doubt on the idea that a multidimensional semantics is warranted for supplements.

After examining a good deal of supplement data and relevant claims made about them, I presented an account that is unique among those that have been proposed to date in that it allows supplements to project while also participating in scope relations and anaphoric links with other content. In this account, important empirical facts related to supplements fall out from more general, and independently motivated, mechanisms. Since an apposition's 
content is treated as essentially being smuggled into its anchor's denotation, supplement scope is just a special case of the ordinary mechanism of operator scope. Anaphora out of and into supplements is just garden-variety discourse anaphora, and cases of quantified supplements, such as the one in the Tibetan Buddhist example (27), can be treated as instances of the phenomenon of telescoping discussed by Roberts (1989, 2005).

Crucially, a supplement that takes widest scope, when proffered, gives rise to a proposal that is separate from the surrounding content. This separation gives a model of supplement projection, since operators can target only the nonsupplement content. It also captures supplement deniability effects by a process related to the recency-based salience of anaphoric antecedents. The scope preferences often observed for supplements are explained by appealing to a more general preference for surface scope over inverse scope. The apparent tendency for supplements to project is also in part derived from this preference, but is additionally influenced by the general preference for anaphoric triggers, including proper names, to be interpreted as closely as possible to the site of their antecedent. And some instances where these preferential readings are preempted are explained by the process of discourse anaphora, just as operator scope may be constrained by discourse anaphora in the general case.

The broad picture I have drawn for supplements, then, is that they are relatively unremarkable, and that many of the notable properties associated with them derive from what goes on around them: the comma intonation, the scope preferences of their anchors, discourse anaphora, contextual influences, etc. In particular, a supplement's projection is not attributed to any special property of supplements, such as not being at-issue, but instead arises as a secondary consequence of the scope of its anchor.

To be sure, more remains to be done. For one thing, as I hinted at the end of Section 3.4.4, a more detailed investigation into the factors influencing when a supplement can be directly denied is in order. I have only suggested that one factor is salience related to the recency of the proposal containing the supplement content, and the exact conditions for felicitous supplement deniability remain somewhat murky. The pragmatic effects on supplement projection due to contextual factors and the availability of alternatives, discussed briefly in Section 2.1.2, need to be investigated too. I have also avoided discussing the fact that supplements can, depending on context, take on either the speaker's or an embedded agent's perspective (Amaral, Roberts \& Smith 2007, Harris \& Potts 2009). But this paper contributes to 
Supplemental update

a much-needed clarification of the empirical status of supplements, and additionally gives a formal model that turns some important generalizations about the supplement data into explicit predictions.

\section{A Technical background}

The semantics developed here is expressed in type theory, which can be thought of as a typed lambda calculus (Barendregt 1980) extended with equality symbols $={ }_{A}$ for every type $A$, and the relations of $\alpha \beta \eta$-conversion expressed as object-language axioms, rather than in the metalanguage. This simple type theory, in the tradition of Church (1940), Henkin (1950, 1963), and Andrews (2002), is further extended with cartesian product types and dependent types parameterized by the natural numbers (Barendregt 1991, 1993, Barthe 1995, Aspinall \& Hofmann 2005, Martin 2013, Martin \& Pollard 2014). In this variant of dependent type theory, products, written $\Pi$, generalize the functions of simple type theory, and sums, written $\Sigma$, generalize simple type-theoretic cartesian products. As usual in dependent type theory, the familiar simple type constructors $\rightarrow$ and $\times$ are, respectively, special cases of $\Pi$ and $\Sigma$ in which the argument types are independent of one another. I mildly abuse this notation when convenient, using the simple type constructors instead of the dependent ones when the dependencies can be safely inferred.

After describing some notational conventions in Section A.1, the static underpinnings of this dynamic semantics are laid out in Section A.2. This static semantics is then extended with natural numbers and product types (Section A.3), the notions of context, content, and update (Section A.4), the dynamic connectives and quantifiers (Section A.5), and dynamic entailment (Section A.6). Definitions for modeling anaphora are given in Section A.7; machinery for handling supplements is given in Section A.8.

\section{A.1 Notational conventions}

I adhere to the following, mostly unsurprising, notational conventions. The type constructor $\rightarrow$ associates to the right, so that $A \rightarrow B \rightarrow C$ is shorthand for $A \rightarrow(B \rightarrow C)$. The constructor $\times$, by contrast, is left associative, and the first and second projection functions $\pi_{1}$ and $\pi_{2}$ are defined as usual. An abstraction of the form $\left(\lambda_{x: A} f\right)$ is often abbreviated $\lambda_{x} . f$, with the typing information stripped off of the variable and . replacing the outer parentheses. Multiple abstractions are often abbreviated by subscripting the 
variable names to a single $\lambda$, with $\lambda_{x y} . f$ usually written instead of $\lambda_{x} \lambda_{y} . f$. Applications are written by enclosing parentheses, with $(f a)$ denoting the application of $f$ to $a$, and associate to the left: $(f a b)$ is shorthand for $((f a) b)$. Outer parentheses are often dropped altogether. An analogous notation to lambda binding is extended to all other quantifiers, so that if $Q:(A \rightarrow B) \rightarrow C$ and $\lambda_{x: A} . P: A \rightarrow B$, I write $\left(Q_{x: A} P\right)$, or simply $Q_{x} \cdot P$, in place of the more clumsy $\left(Q \lambda_{x: A} \cdot P\right)$.

Vector notation is used for the inhabitants of cartesian product types (Definition A.8): for terms of type $A^{n}, \mathbf{x}: A^{n}$ abbreviates $\left\langle x_{0}, \ldots, x_{n-1}\right\rangle: A^{n}$. When a vector appears as a bound variable, I often superscript it with its length when it first appears, for example $\lambda_{\mathrm{x}^{n} .} f: A^{n} \rightarrow B$. Since it is sometimes convenient to identify the various coordinates of a bound vector variable, I sometimes write an $n$-ary vector as a series of $n$ bound variables separated by commas: letting $\mathbf{x}: A^{3}, \lambda_{x, y, z} \cdot f$ is shorthand for $\lambda_{\mathbf{x}^{3}} \cdot f$. The concatenation of two vectors $\mathbf{x}$ and $\mathbf{y}$ is written $\mathbf{x}, \mathbf{y}$; the vector that results from appending a new coordinate $y$ to the end of a vector $\mathbf{x}$ is written $\mathbf{x}, y$. Whenever $\mathbf{y}: A^{0}$ is empty and $\mathbf{x}: A^{n}$ is some vector, I write $\mathbf{x}$ to abbreviate both $\mathbf{x}, \mathbf{y}$ and $\mathbf{y}, \mathbf{x}$. Finally, a single-coordinate vector $\mathbf{x}: A^{1}$ is often written as just $x$, where $x: A$ is understood as taking up the sole coordinate $x_{0}$ of $\mathbf{x}$.

\section{A.2 The underlying static semantics}

The semantic theory itself is an extension of Pollard's (2015) agnostic hyperintensional semantics (AHS) with the basic nonlogical types e (entities), $p$ (propositions), and $\mathrm{w}$ (worlds), in addition to the logical types $\mathrm{t}$ (truth values) and 1 (unit).

Definition A.1 (Sense types). The set of sense types is formed from e and $\mathrm{p}$ and all the types that can be recursively built from them using the constructors $\rightarrow$ and $\times$.

Definition A.2 (Extension types). For each sense type $A$, the extension type of $A$ is written $\operatorname{Ext}(A)$ and defined as follows, for $A$ and $B$ sense types:

$$
\begin{aligned}
& \operatorname{Ext}(\mathrm{e})==_{\text {def }} \mathrm{e} \\
& \operatorname{Ext}(\mathrm{p})={ }_{\text {def }} \mathrm{t} \\
& \operatorname{Ext}(A \rightarrow B)={ }_{\text {def }} A \rightarrow \operatorname{Ext}(B) \\
& \operatorname{Ext}(A \times B)={ }_{\text {def }} \operatorname{Ext}(A) \times \operatorname{Ext}(B)
\end{aligned}
$$


Supplemental update

That is, the extension type of the type e of entities is just e itself, and the truth-value type $t$ is the extension type of the type of propositions. In particular, the extension of the property type $\mathrm{e} \rightarrow \mathrm{p}$ is the type $\operatorname{Ext}(\mathrm{e} \rightarrow \mathrm{p})=$ $\mathrm{e} \rightarrow \operatorname{Ext}(\mathrm{p})=\mathrm{e} \rightarrow \mathrm{t}$, the type of (characteristic functions of) sets of entities.

Definition A.3 (Extension functions). For every sense type $A$, there is a corresponding nonlogical constant $@_{A}: A \rightarrow \mathrm{w} \rightarrow \operatorname{Ext}(A)$, called the extension function for $A$, and subject to the following axioms:

$$
\begin{aligned}
& \vdash \forall_{x: \mathrm{e}} \forall_{w: \mathrm{w}} \cdot x @_{\mathrm{e}} w=x \\
& \vdash \forall_{f: A \rightarrow B} \forall_{w: \mathrm{w}} \cdot\left(f @_{A \rightarrow B} w\right)=\lambda_{x: A} \cdot(f x) @_{B} w \\
& \vdash \forall_{c: A \times B} \forall_{w: \mathrm{w}} \cdot\left(c @_{A \times B} w\right)=\left\langle\left(\pi_{1} c\right) @_{A} w,\left(\pi_{2} c\right) @_{B} w\right\rangle
\end{aligned}
$$

In the case $A=\mathrm{p}$, the function $@_{\mathrm{p}}$ tests whether a given proposition is true at a given world. Note that the semantic theory itself does not need to take a position on exactly how @ $@_{\mathrm{p}}$ is defined, as long as some way to evaluate the truth value of a proposition is, in principle, available. See Plummer \& Pollard 2012 for a detailed comparison of two important implementations of $@_{\mathrm{p}}$.

Definition A.4 (Sense equivalence). Equivalence between senses is expressed via the nonlogical constant $\equiv_{A}: A \rightarrow A \rightarrow \mathrm{t}$, for $A$ a sense type, defined as

$$
\equiv_{A}=_{\text {def }} \lambda_{a: A} \lambda_{b: A} \forall_{w: w} \cdot\left(a @_{A} w\right)=\left(b @_{A} w\right) .
$$

That is, two senses are equivalent if they have the same extension at every world.

Definition A.5 (Entailment). Entailment between two propositions is encoded by entails $: p \rightarrow p \rightarrow t$, and is given the definition in

$$
\text { entails }=_{\text {def }} \lambda_{p: p} \lambda_{q: p} \forall_{w: w} \cdot\left(p @_{\mathrm{p}} w\right) \Rightarrow\left(q @_{\mathrm{p}} w\right),
$$

which simply states that $p$ entails $q$ just in case at every world $w, q$ is true at $w$ provided $p$ is.

Given Definitions A.4 and A.5, we have the following:

Theorem A.1. $\vdash \forall_{p: p} \forall_{q: p \cdot}((p$ entails $q) \wedge(q$ entails $p)) \Leftrightarrow p \equiv_{p} q$.

This result establishes propositional equivalence as mutual entailment, and its proof, which is straightforward, is sketched by Martin (2013: theorem 3.8). 
Definition A.6 (Intensional equality). The function equals ${ }_{A}: A \rightarrow A \rightarrow \mathrm{p}$ compares two terms of some sense type $A$ for intensional equality, and is subject to the axiom

$$
\vdash \forall_{a: A} \forall_{b: A} \forall_{w: w} .\left(a \text { equals }_{A} b\right) @ w \Leftrightarrow a=b .
$$

Definition A.7 (Propositional connectives and quantifiers). The nullary connectives true and false are respectively a necessarily true and a necessarily false proposition. Analogs of the familiar logical connectives are available at the propositional level as not, and, implies, and or. For each sense type $A$, the universal quantifier forall ${ }_{A}$ and the existential quantifier exists ${ }_{A}$ are available, both with type $(A \rightarrow \mathrm{p}) \rightarrow \mathrm{p}$; the subscript $A$ is dropped in practice. These connectives are subject to the following axioms, where $A$ is a sense type:

$$
\begin{aligned}
& \vdash \forall_{w: \mathrm{w}} \cdot \operatorname{true} @_{\mathrm{p}} w \\
& \vdash \forall_{w: \mathrm{w}} \cdot \neg\left(\text { false } @_{\mathrm{p}} w\right) \\
& \vdash \forall_{p: \mathrm{p}} \forall_{w: \mathrm{w} \cdot} \cdot\left((\operatorname{not} p) @_{\mathrm{p}} w\right) \Leftrightarrow \neg\left(p @_{\mathrm{p}} w\right) \\
& \vdash \forall_{p: \mathrm{p}} \forall_{q: \mathrm{p}} \forall_{w: \mathrm{w}} \cdot\left((p \text { and } q) @_{\mathrm{p}} w\right) \Leftrightarrow\left(\left(p @_{\mathrm{p}} w\right) \wedge\left(q @_{\mathrm{p}} w\right)\right) \\
& \vdash \forall_{p: \mathrm{p}} \forall_{q: \mathrm{p}} \forall_{w: \mathrm{w}} \cdot\left((p \text { implies } q) @_{\mathrm{p}} w\right) \Leftrightarrow\left(\left(p @_{\mathrm{p}} w\right) \Rightarrow\left(q @_{\mathrm{p}} w\right)\right) \\
& \vdash \forall_{p: \mathrm{p}} \forall_{q: \mathrm{p}} \forall_{w: \mathrm{w}} \cdot\left((p \text { or } q) @_{\mathrm{p}} w\right) \Leftrightarrow\left(\left(p @_{\mathrm{p}} w\right) \vee\left(q @_{\mathrm{p}} w\right)\right) \\
& \vdash \forall_{P: A \rightarrow \mathrm{p}} \forall_{w: \mathrm{w} \cdot}\left(\left(\text { forall }_{A} P\right) @_{\mathrm{p}} w\right) \Leftrightarrow \forall_{x: A} \cdot(P x) @_{\mathrm{p}} w \\
& \vdash \forall_{P: A \rightarrow \mathrm{p}} \forall_{w: \mathrm{w} \cdot}\left(\left(\operatorname{exists}_{A} P\right) @_{\mathrm{p}} w\right) \Leftrightarrow \exists_{x: A} \cdot(P x) @_{\mathrm{p}} w
\end{aligned}
$$

Since AHS is built on top of type theory, models of truth and validity are straightforwardly available as instances of Henkin's (1950) general models.

\section{A.3 Natural numbers and cartesian products}

We next add the basic type n, of natural numbers, to the underlying type theory, which must be suitably axiomatized as a natural number type (see Andrews 2002 for one approach).

Definition A.8 (Cartesian product types). For each type $A$, the $n$-ary cartesian product types as follows:

$$
\begin{aligned}
A^{0} & =\operatorname{def} 1 \\
A^{1} & =\operatorname{def} A \\
A^{n+1} & =\operatorname{def} A^{n} \times A \quad(n>0)
\end{aligned}
$$


Supplemental update

Intuitively, the type $A^{n}$ is the type of lists of $n$ inhabitants of the type $A$, with the type of zero-length lists identified with the unit 1 , and singleton lists with the type $A$ itself.

\section{A.4 Contexts, contents, and updates}

Definition A.9 (Contexts). Discourse contexts have the type

$$
\mathrm{c}_{n}=_{\mathrm{def}} \mathrm{e}^{n} \rightarrow \mathrm{p},
$$

the type of functions from an $n$-ary vector of entities to a proposition. The arity of a context $c: c_{n}$, written $|c|$, is defined to be $n$. The type c is the type of contexts of any arity, and is implemented via the dependent sum $\mathrm{c}=_{\text {def }} \sum_{n: \mathrm{n}} \cdot \mathrm{c}_{n}$.

The type c can be thought of as the disjoint union of all the types $c_{n}$.

Definition A.1o (Contexts of bounded arity). The type of contexts of arity at least $n$ is defined as

$$
\mathrm{c}_{\geq n}=_{\text {def }} \Sigma_{m: n} \cdot \mathrm{c}_{n+m},
$$

and contexts strictly larger than $n$ have the type $\mathrm{c}_{>n}={ }_{\operatorname{def}} \mathrm{C}_{\geq n+1}$.

Definition A.11 (Contents). The meanings of declaratives are modeled as contents, after Roberts's (2012b) proffered contents. Their type is defined as

$$
\mathrm{k}_{n}=_{\mathrm{def}} \Pi_{c: \mathrm{c}_{m}} \cdot \mathrm{c}_{m+n},
$$

essentially, the type of transitions from an input context to an output context that introduce $n$ discourse referents. That is, a content of type $\mathrm{k}_{n}$ takes an input context of arity $m$ to return a context whose arity is $m+n$. The number of discourse referents introduced by a content is its degree, written $|k|$, and for $k: \mathrm{k}_{n}$, defined to be $n$. The type $\mathrm{k}={ }_{\text {def }} \Sigma_{n: n} \cdot \mathrm{k}_{n}$ is the type of contents of any degree.

Definition A.12 (Updates). To capture the difference between declarative meanings and proposals, the type $\mathrm{u}_{n}$, of updates, is introduced that is the same as $\mathrm{k}_{n}$ at the type level, but has a different function:

$$
\mathrm{u}_{n}=_{\mathrm{def}} \Pi_{c: \mathrm{c}_{m}} \cdot \mathrm{c}_{m+n} .
$$

The type $\mathrm{u}={ }_{\text {def }} \Sigma_{n: n} \cdot \mathrm{u}_{n}$ is the type of updates of any arity. 
Definition A.13 (Context change). The context change function cc: $\mathrm{k}_{n} \rightarrow \mathrm{u}_{n}$ promotes a content to an update (i.e., proposal), and is defined as

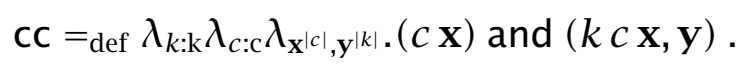

In contrast to contents, updates incorporate the carryover from the input context into the output. Given a content $k$, cc returns a function that takes a context $c$ to a new context of arity $|c|+|k|$. This new context integrates the information $(c \mathbf{x})$ already present in the input context with the proposition $(k c \mathbf{x}, \mathbf{y})$, which is obtained by interpreting $k$ in the context $c$.

\section{A.5 Dynamic connectives and quantifiers}

Definition A.14 (Dynamic connectives). Dynamic conjunction AND : $\mathrm{k}_{m} \rightarrow$ $\mathrm{k}_{n} \rightarrow \mathrm{k}_{m+n}$ and dynamic negation NOT $: \mathrm{k}_{n} \rightarrow \mathrm{k}_{0}$ are defined as follows, as are dynamic disjunction OR and dynamic implication IMPLIES, both with type $\mathrm{k}_{m} \rightarrow \mathrm{k}_{n} \rightarrow \mathrm{k}_{0}$, which are both defined in terms of AND and NOT:

$$
\begin{aligned}
& \text { AND }=_{\text {def }} \lambda_{h: k} \lambda_{k: k} \lambda_{c: c} \lambda_{\mathbf{x}^{|c|}, \mathbf{y}^{|h|}, \mathbf{z}^{|k|} .}(h c \mathbf{x}, \mathbf{y}) \text { and }(k(c c h c) \mathbf{x}, \mathbf{y}, \mathbf{z}) \\
& \text { THAT }=_{\text {def }} \lambda_{D: d_{1}} \lambda_{E: d_{1}} \lambda_{n: \mathrm{n} .} .(D n) \text { AND }(E n) \\
& \text { NOT }=_{\text {def }} \lambda_{k: k} \lambda_{c: c} \lambda_{\mathbf{x}^{|c|} \text {.not exists }} \mathbf{y}^{|k|} .(k c \mathbf{x}, \mathbf{y}) \\
& \mathrm{OR}={ }_{\text {def }} \lambda_{h: \mathrm{k}} \lambda_{k: \mathrm{k}} \text {.NOT }((\text { NOT } h) \text { AND }(\text { NOT } k)) \\
& \text { IMPLIES }=_{\text {def }} \lambda_{h: \mathrm{k}} \lambda_{k: \mathrm{k}} \cdot(\text { NOT } h) \text { OR }(h \text { AND } k)
\end{aligned}
$$

In a dynamic conjunction, the second conjunct $k$ is interpreted in the context that results from applying the first conjunct $h$ to the input context $c$ of the entire conjunction; dynamic property conjunction THAT is defined by analogy to its static counterpart. As for dynamic negation, all of the $|k|$ discourse referents introduced by $k$ become existentially bound in the scope of NOT, reminiscent of Heim's (1982) "existential closure", with the resulting proposition negated.

Dynamic disjunction oR is defined by DeMorgan duality, and, like dynamic implication IMPLIES, is also defined entirely in terms of other connectives. The definition of implication in (A.8) avoids the asymmetry problem (Rooth 1987, Kanazawa 1994, Chierchia 1995) because the weak reading of implication is made the default, adapting Chierchia's (1995) idea of dynamic conservativity. 
Supplemental update

Definition A.15 (Parataxis). The operation of discourse parataxis is modeled by the composition function $\circ: \mathrm{u}_{m} \rightarrow \mathrm{u}_{n} \rightarrow \mathrm{u}_{m+n},{ }^{8}$ defined as

$$
\circ={ }_{\mathrm{def}} \lambda_{u: \mathrm{u}} \lambda_{v: \mathrm{u}} \lambda_{c: c} \cdot v(u c) \text {. }
$$

We then have the following relationship between dynamic conjunction of updates and parataxis.

Theorem A.2 (Conjoined update is equivalent to parataxis).

$$
\vdash \forall_{h: k} \forall_{k: k} \cdot \mathrm{cc}(h \text { AND } k)=(\mathrm{cc} h) \circ(\mathrm{cc} k) \text {. }
$$

Martin (2013: theorem 4.22) gives a straightforward proof similar to the following.

Proof. Let $h: \mathrm{k}$ and $k: \mathrm{k}$. We then reason as follows:

$$
\begin{aligned}
& \vdash \mathrm{CC}(h \text { AND } k) \\
& =\operatorname{cc}\left(\lambda_{c} \lambda_{\mathbf{x}^{|c|}, \mathbf{y}^{|h|}, \mathbf{z}^{|k|}}(h c \mathbf{x}, \mathbf{y}) \text { and }(k(\operatorname{cch} c) \mathbf{x}, \mathbf{y}, \mathbf{z})\right) \quad \text { (by (A.4)) }
\end{aligned}
$$

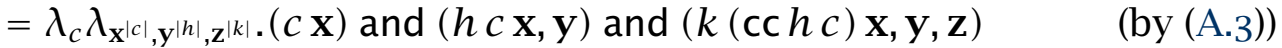

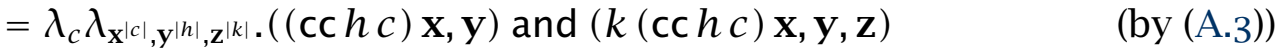

$$
\begin{aligned}
& =\lambda_{c} \cdot\left(\left(\lambda_{d} \lambda_{\mathbf{u}^{|d|}, \mathbf{v}^{|k|}}(d \mathbf{u}) \text { and }(k d \mathbf{u}, \mathbf{v})\right)(\operatorname{cc} h c)\right) \quad(\beta \text {-expansion }) \\
& =\lambda_{c} \cdot(\operatorname{cc} k(\operatorname{cch} c)) \\
& \text { (by (A.3)) } \\
& =(\mathrm{cc} h) \circ(\mathrm{cc} k): \mathrm{u}
\end{aligned}
$$

Definition A.16 ( $n$-ary static properties). The types of $n$-ary static properties are defined recursively as follows:

$$
\begin{gathered}
\mathrm{p}_{0}={ }_{\text {def }} \mathrm{p} \\
\mathrm{p}_{n+1}={ }_{\text {def }} \mathrm{e} \rightarrow \mathrm{p}_{n}
\end{gathered}
$$

Definition A.17 ( $n$-ary dynamic properties). Dynamic properties of arity o-3 are defined as follows:

$$
\begin{aligned}
& \mathrm{d}_{0, i}={ }_{\text {def }} \mathrm{k}_{i} \\
& \mathrm{~d}_{1, i}={ }_{\text {def }} \Pi_{n: \mathrm{n}} \Pi_{c: \mathrm{C}_{>n}} \cdot \mathrm{c}_{|c|+i} \\
& \mathrm{~d}_{2, i}={ }_{\text {def }} \Pi_{m: \mathrm{n}} \Pi_{n: \mathrm{n}} \Pi_{c: \mathrm{c}_{>(\max m n)}} \cdot \mathrm{c}_{|\mathcal{c}|+i} \\
& \mathrm{~d}_{3, i}={ }_{\operatorname{def}} \Pi_{k: \mathrm{n}} \Pi_{m: \mathrm{n}} \Pi_{n: \mathrm{n}} \cdot \Pi_{c: \mathrm{c}_{>}(\max k m n)} \cdot \mathrm{c}_{|c|+i}
\end{aligned}
$$

8 General function composition is usually written with the composed functions in the other order. I use the opposite order here to emphasize the sequential nature of discourse update. 
The dependent type restrictions ensure that a dynamic property that takes a discourse referent $n$ as its argument is only interpretable in contexts of arity at least $n$. Here the max functions select the largest among a list of natural numbers; see Martin 2013: definition 4.2 for more.

For each $n$ and $i$, the type of dynamic properties whose underlying content introduces $i$ referents is the dependent sum $\mathrm{d}_{n}={ }_{\text {def }} \sum_{i \mathrm{n}} \cdot \mathrm{d}_{n, i}$, so that, for example, $\mathrm{d}_{1}={ }_{\mathrm{def}} \sum_{i: \mathrm{n}} \cdot \mathrm{d}_{1, i}$. In practice, the second subscript on the types $\mathrm{d}_{n, i}$ is often dropped when irrelevant.

Definition A.18 (Dynamicization). The dynamicizer functions $d_{y n}: \mathrm{p}_{n} \rightarrow \mathrm{d}_{n}$ map a static property of any arity to its corresponding dynamic variant. For arities $\mathbf{O}^{-3}$, the dynamicizer functions are defined as follows:

$$
\begin{aligned}
& \operatorname{dyn}_{0}={ }_{\text {def }} \lambda_{p: \mathrm{p}} \lambda_{c: \mathrm{c}} \lambda_{\mathbf{x}^{|c|} \cdot p} \\
& \operatorname{dyn}_{1}={ }_{\text {def }} \lambda_{P: \mathrm{p}_{1}} \lambda_{n: \mathrm{n}} \lambda_{c: \mathrm{c}>n} \lambda_{\mathbf{x}^{|c|} .}\left(P x_{n}\right) \\
& \left.\operatorname{dyn}_{2}={ }_{\text {def }} \lambda_{R: \mathrm{p}_{2}} \lambda_{m: \mathrm{n}} \lambda_{n: \mathrm{n}} \lambda_{c: \mathrm{c}_{>}(\max m n)} \lambda_{\mathbf{x}^{|c|} \cdot\left(R x_{m}\right.} x_{n}\right) \\
& \operatorname{dyn}_{3}={ }_{\text {def }} \lambda_{R: \mathrm{p}_{3}} \lambda_{k: \mathrm{n}} \lambda_{m: \mathrm{n}} \lambda_{n: \mathrm{n}} \lambda_{c: \mathrm{C}_{>}(\max k m n)} \lambda_{\mathbf{x}^{|c|} .}\left(R x_{k} x_{m} x_{n}\right)
\end{aligned}
$$

Dynamic properties of higher arities can be generated from their static counterparts by extending dyn in the obvious way.

Definition A.19 (Context extension). The context extension function $(\cdot)^{+}$: $\mathrm{c}_{n} \rightarrow \mathrm{c}_{n+1}$ adds the next discourse referent to a context, and is defined as

$$
(\cdot)^{+}={ }_{\text {def }} \lambda_{c: c} \lambda_{\mathbf{x}^{|c|}, y} \cdot \mathbf{C} \mathbf{x},
$$

where the variable $y$ does not occur in $\mathbf{x}$ and does not occur free in $c$.

Definition A.20 (Dynamic quantifiers). The dynamic existential EXISTS, with type $\mathrm{d}_{1, i} \rightarrow \mathrm{k}_{i+1}$, and dynamic universal FORALL $: \mathrm{d}_{1, i} \rightarrow \mathrm{k}_{0}$ are defined as follows:

$$
\begin{aligned}
& \text { EXISTS }={ }_{\text {def }} \lambda_{D: \mathrm{d}_{1}} \lambda_{c: c} \cdot D|c| c^{+} \\
& \text {FORALL }=_{\text {def }} \lambda_{D: \mathrm{d}_{1}} \cdot \text { NOT EXISTS } \\
& n \cdot \text { NOT }(D n)
\end{aligned}
$$

The dynamic existential thus takes a dynamic property $D$ and passes to it the next discourse referent $|c|$ along with the context $c^{+}$, a minimal extension of $c$ that has a discourse referent at coordinate $|c|$. The dynamic universal, by contrast, closes off the accessibility of any discourse referents introduced within its scope, via the outermost dynamic negation. 
Supplemental update

Definition A.21 (Predicativization). The predicativizer PRED, whose type is $\left(\mathrm{d}_{1} \rightarrow \mathrm{k}_{i}\right) \rightarrow \mathrm{d}_{1, i}$, derives a dynamic property from a dynamic GQ, with the definition

$$
\operatorname{PRED}=_{\mathrm{def}} \lambda_{Q: \mathrm{d}_{1} \rightarrow \mathrm{k}_{i}} \lambda_{n: \mathrm{n}} \cdot Q_{m} \cdot m \text { EQUALS } n,
$$

where EQUALS $=_{\text {def }} \lambda_{m: n} \lambda_{n: n} \lambda_{c: c_{>(\max m n)}} \lambda_{\mathbf{x}^{|c|}} . m$ equals $s_{\mathrm{n}} n$.

Definition A.22 (Dynamic determiners). Some important dynamic determiners are the indefinite $\mathrm{A}: \mathrm{d}_{1, i} \rightarrow \mathrm{d}_{1, j} \rightarrow \mathrm{k}_{i+j+1}$, negated indefinite NO, and universal EVERY, both of type $\mathrm{d}_{1} \rightarrow \mathrm{d}_{1} \rightarrow \mathrm{k}_{0}$.

$$
\begin{aligned}
& \mathrm{A}={ }_{\mathrm{def}} \lambda_{D: \mathrm{d}_{1}} \lambda_{E: \mathrm{d}_{1}} \cdot \operatorname{EXISTS}_{n} \cdot(D n) \text { AND }(E n) \\
& \mathrm{NO}={ }_{\text {def }} \lambda_{D: \mathrm{d}_{1}} \lambda_{E: \mathrm{d}_{1}} \cdot \mathrm{NOT}(\mathrm{A} D E) \\
& \text { EVERY }=_{\mathrm{def}} \lambda_{D: \mathrm{d}_{1}} \lambda_{E: \mathrm{d}_{1}} \cdot \text { FORALL }_{n} \cdot(D n) \text { IMPLIES }(E n)
\end{aligned}
$$

\section{A.6 Dynamic entailment}

Definition A.23 (Context entailment). Entailment between two contexts is encoded by the context entailment function c-entails : $\Pi_{c: c} \Pi_{d: c_{z|c|}} . t$, defined as

$$
\text { c-entails }=_{\text {def }} \lambda_{c: c} \lambda_{d: c_{\geq|c|}} \forall_{\mathbf{x}^{|c|}} .(c \mathbf{x}) \text { entails exists } \mathbf{y}_{\mathbf{y}||-|c|}(d \mathbf{x}, \mathbf{y}) .
$$

In words, this definition says that a context $c$ entails another context $d$ of equal or greater arity if for every input vector $\mathbf{x}$ of arity $|c|$, the proposition $(c \mathbf{x})$ entails that there is a vector $\mathbf{y}$ such that $\mathbf{x}, \mathbf{y}$ has $|d|$ coordinates and $(d \mathbf{x}, \mathbf{y})$.

Related notions are those of entailment and consistency between a context and a content.

Definition A.24 (Content entailment). Whether the update derived from a given content would be entailed by a certain context can be determined via the content entailment function k-entails $: \mathrm{c} \rightarrow \mathrm{k} \rightarrow \mathrm{t}$, with the definition

$$
\text { k-entails }=_{\text {def }} \lambda_{c: c} \lambda_{k: \mathrm{k}} \cdot c \text { c-entails }(\mathrm{cc} k c) .
$$

Definition A.25 (Content consistency). Testing whether a content $k$ is consistent with a context $c$ is handled by the content consistency function k-cons, with the same type as k-entails, and defined as

$$
\mathrm{k} \text {-cons }=_{\mathrm{def}} \lambda_{c: \mathrm{c}} \lambda_{k: \mathrm{k}} \cdot \neg(c \text { k-entails }(\text { NOT } k)),
$$

that is, k-cons tests whether $c$ contextually entails the dynamic negation of $k$. 
Scott Martin

\section{A.7 Definite anaphora}

Definites, pronouns and names all get a generalized quantifier analysis in this dynamic semantics. These anaphoric triggers select the uniquely most salient antecedent such that the context entails the antecedent to have the relevant descriptive content, though a theory of salience is merely assumed but not defined. Since definiteness is modeled using the description operator, anaphoric infelicity is signaled via a distinguished inhabitant of the antecedent's type that is reserved for the case when no suitable antecedent is available, following Henkin (1963).

Definition A.26 (Generalized definiteness). The generalized definiteness function the $: \mathrm{d}_{1} \rightarrow \mathrm{c} \rightarrow \mathrm{n}$ selects the unique discourse referent in the context whose corresponding entity is entailed to have a given property. It is defined as

$$
\text { the } \left.=_{\text {def }} \lambda_{D: \mathrm{d}_{1}} \lambda_{c: c}\right\urcorner_{n: \mathrm{n}} \cdot(n<|c|) \wedge c \text { k-entails }(D n) \text {. }
$$

Since pronouns only require consistency with their antecedents (see Martin 2013: chapter 2), definiteness for pronouns is defined slightly differently.

Definition A.27 (Pronominal definiteness). The pronominal definiteness function has the same type as the in Definition A.26, but is defined as follows:

$$
\text { pro } \left.=_{\text {def }} \lambda_{D: d_{1}} \lambda_{c: c}\right\urcorner_{n: n} \cdot(n<|c|) \wedge c \text { k-cons }(D n)
$$

The important difference between the and pro is that pro only requires consistency (via k-cons), while the demands full entailment (via k-entails).

Definition A.28 (Dynamic definite determiners). The dynamic definite determiners THE and PRO, both with type $\mathrm{d}_{1} \rightarrow \mathrm{d}_{1, i} \rightarrow \mathrm{k}_{i}$, are defined based on the and pro:

$$
\begin{aligned}
& \text { THE }={ }_{\text {def }} \lambda_{D: \mathrm{d}_{1}} \lambda_{E: \mathrm{d}_{1}} \lambda_{c: c} \cdot E(\text { the } D c) \\
& \text { PRO }={ }_{\text {def }} \lambda_{D: \mathrm{d}_{1}} \lambda_{E: \mathrm{d}_{1}} \lambda_{c: c} \cdot E(\operatorname{pro} D c)
\end{aligned}
$$

Definition A.29 (Dynamic definites). The dynamic definites are defined in terms of THE and PRO. For example, the dynamic meaning of the proper name Kim is $\mathrm{KIM}: \mathrm{d}_{1, i} \rightarrow \mathrm{k}_{i}$, defined as

$$
\mathrm{KIM}={ }_{\text {def }} \text { THE NAMED-KIM },
$$


Supplemental update

where NAMED-KIM is the dynamic property of being named "Kim", derived from its static counterpart named-kim by $\mathrm{dyn}_{1}$. Other proper names are assigned similar dynamic meanings.

All of the following also have the type $d_{1, i} \rightarrow k_{i}$ of dynamic GQs:

$$
\begin{aligned}
& \text { HE }=_{\text {def }} \text { PRO MALE } \\
& \text { HIM }=_{\text {def }} \text { PRO MALE } \\
& \text { SHE }=_{\text {def }} \text { PRO FEMALE } \\
& \text { HER }=_{\text {def }} \text { PRO FEMALE } \\
& \mathrm{IT}==_{\text {def }} \text { PRO NONHUMAN }
\end{aligned}
$$

where MALE, FEMALE, and NONHUMAN are obtained from their respective static counterparts male, female, and nonhuman via dyn . $_{\text {. }}$

Possessive determiners can also be defined based on property conjunction, THE, and the other definites, for example, his, which has the same type as THE:

$$
\text { HIS }=_{\text {def }} \lambda_{D: \mathrm{d}_{1}} \lambda_{E: \mathrm{d}_{1}} \text {.THE }\left(D \text { THAT } \lambda_{n} \text {.HE }(\text { HAVE } n)\right) E
$$

Here, HAVE is generated by $\mathrm{dyn}_{2}$ from its static counterpart have.

\section{A.8 Machinery specific to the analysis of supplements}

Definition A.30 (Comma intonation). The comma intonation COMMA, which has the type $\left(\mathrm{d}_{1} \rightarrow \mathrm{k}_{i}\right) \rightarrow \mathrm{d}_{1, j} \rightarrow \mathrm{d}_{1, k} \rightarrow \mathrm{k}_{i+j+k}$, demarcates a supplement from surrounding content, and has the definition

$$
\text { COMMA }=_{\text {def }} \lambda_{Q D E} \cdot(Q D) \text { AND }(\operatorname{THE} D E) .
$$

\section{References}

Amaral, Patricia, Craige Roberts \& E. Allyn Smith. 2007. Review of The Logic of Conventional Implicatures by Chris Potts. Linguistics and Philosophy 30(6). 707-749. http://dx.doi.org/10.1007/s10988-008-9025-2.

AnderBois, Scott, Adrian Brasoveanu \& Robert Henderson. 2010. Crossing the appositive/at-issue meaning boundary. In Semantics and Linguistic Theory (SALT) 20, 328-346. http://dx.doi.org/10.3765/salt.v20io.2551.

AnderBois, Scott, Adrian Brasoveanu \& Robert Henderson. 2015. At-issue proposals and appositive impositions in discourse. Journal of Semantics 32(1). 93-138. http://dx.doi.org/10.1093/jos/ffto14. 
Andrews, Peter B. 2002. An introduction to mathematical logic and type theory: To truth through proof. Vol. 27 (Applied Logic Series). Dordrecht: Kluwer Academic Publishers. http://dx.doi.org/10.1007/978-94-015-9934-4.

Asher, Nicholas \& Sylvain Pogodalla. 2011. SDRT and continuation semantics. In Takashi Onada, Daisuke Bekki \& Eric McCready (eds.), New frontiers in artificial intelligence (Lecture Notes in Computer Science 6797), 3-15. Berlin \& Heidelberg: Springer. http://dx.doi.org/10.1007/978-3-642-25655-4_2.

Aspinall, David \& Martin Hofmann. 2005. Dependent types. In Benjamin C. Pierce (ed.), Advanced topics in types and programming languages, 45-86. Cambridge, MA: MIT Press.

Barendregt, Henk. 1980. The lambda calculus: Its syntax and semantics. Vol. 103 (Studies in Logic and the Foundations of Mathematics). Amsterdam: North-Holland.

Barendregt, Henk. 1991. Introduction to generalized type systems. Journal of Functional Programming 1(2). 125-154.

Barendregt, Henk. 1993. Lambda calculi with types. In Samson Abramsky, Dov M. Gabbay \& Thomas S. E. Maibaum (eds.), Handbook of logic in computer science, vol. 2, 117-309. New York: Oxford University Press.

Barker, Chris, Rafaella Bernardi \& Chung-chieh Shan. 2010. Principles of interdimensional meaning interaction. In Semantics and Linguistic Theory (SALT) 20, 109-127. http://dx.doi.org/10.3765/salt.v20io.2569.

Barker, Chris \& Chung-chieh Shan. 2014. Continuations and natural language (Oxford Studies in Theoretical Linguistics 53). New York \& Oxford: Oxford University Press.

Barthe, Gilles. 1995. Extensions of pure type systems. In Mariangiola DezaniCiancaglini \& Gordon Plotkin (eds.), Typed lambda calculi and applications (Lecture Notes in Computer Science 902), 16-31. Berlin \& Heidelberg: Springer. http://dx.doi.org/10.1007/BFboo14042.

Barwise, Jon \& Robin Cooper. 1981. Generalized quantifiers and natural language. Linguistics and Philosophy 4(2). 159-219. http://dx.doi.org/10. 1007/BFo0350139.

Beaver, David I. 2001. Presupposition and assertion in dynamic semantics. Stanford, CA: CSLI Publications.

Blackburn, Patrick \& Johan Bos. 1999. Representation and inference for natural language: A first course in computational semantics. Vol. 2 (Working with Discourse Representation Structures). Unpublished draft (September 3, 1999). http://www.let.rug.nl/bos/comsem/book2.html. 
Supplemental update

Bos, Johan. 2003. Implementing the binding and accommodation theory for anaphora resolution and presupposition projection. Computational Linguistics 29(2). 179-210. http://dx.doi.org/10.1162/o89120103322145306. Chierchia, Gennaro. 1995. The dynamics of meaning: Anaphora, presupposition, and the theory of grammar. University of Chicago Press. http: //dx.doi.org/10.7208/chicago/9780226104515.001.0001.

Church, Alonzo. 1940. A formulation of the simple theory of types. Journal of Symbolic Logic 5(2). 56-68. http://dx.doi.org/10.2307/2266170.

Geurts, Bart. 1999. Presuppositions and pronouns. Vol. 3 (Current Research in the Semantics/Pragmatics Interface). Oxford: Elsevier.

Ginzburg, Jonathan. 2012. The interactive stance. New York \& Oxford: Oxford University Press. http://dx.doi.org/10.1093/acprof:oso/9780199697922. o01.0001.

Giorgolo, Gianluca \& Ash Asudeh. 2012. $\langle M, \eta, \star\rangle$ monads for conventional implicatures. In Ana Aguilar Guevara, Anna Chernilovskaya \& Rick Nouwen (eds.), Sinn und Bedeutung 16, vol. 1, 265-278. Cambridge, MA: MIT Working Papers in Linguistics.

del Gobbo, Francesca. 2007. On the syntax and semantics of appositive relative clauses. In Nicole Dehé \& Yordanka Kavalova (eds.), Parentheticals, 173-201. Amsterdam \& Philadelphia, PA: John Benjamins. http://dx.doi. org/10.1075/la.106.10del.

Groenendijk, Jeroen \& Martin Stokhof. 1991. Dynamic predicate logic. Linguistics and Philosophy 14(1). 39-100. http://dx.doi.org/10.1007/BFoo628304. de Groote, Philippe. 2006. Towards a Montagovian account of dynamics. In Semantics and Linguistic Theory (SALT) 16, 1-16. http://dx.doi.org/10. 3765/salt.v16io.2952.

Harris, Jesse A. \& Christopher Potts. 2009. Perspective-shifting with appositives and expressives. Linguistics and Philosophy 32(6). 523-552. http: //dx.doi.org/10.1007/s10988-010-9070-5.

Heim, Irene. 1982. The semantics of definite and indefinite noun phrases. University of Massachusetts, Amherst dissertation.

Henkin, Leon. 1950. Completeness in the theory of types. Journal of Symbolic Logic 15(2). 81-91. http://dx.doi.org/10.2307/2266967.

Henkin, Leon. 1963. A theory of propositional types. Fundamenta Mathematicae 52(1). 323-344.

Huddleston, Rodney \& Geoffrey K. Pullum. 2002. The Cambridge grammar of the English language. Cambridge: Cambridge University Press. 
Kamp, Hans. 1981. A theory of truth and semantic representation. In Paul Portner \& Barbara H. Partee (eds.), Formal semantics: The essential readings, 189-222. Oxford: Blackwell.

Kamp, Hans \& Uwe Reyle. 1993. From discourse to logic: Introduction to modeltheoretic semantics of natural language, formal logic, and discourse representation theory (Studies in Linguistics and Philosophy 42). Dordrecht: Springer. http://dx.doi.org/10.1007/978-94-017-1616-1.

Kanazawa, Makoto. 1994. Weak vs. strong readings of donkey sentences and monotonicity inference in a dynamic setting. Linguistics and Philosophy 17(2). 109-158. http://dx.doi.org/10.1007/BFoog84775.

Karttunen, Lauri \& Stanley Peters. 1979. Conventional implicature. In ChoonKyu Oh \& David A. Dineen (eds.), Presupposition, vol. 11 (Syntax and Semantics), 1-56. New York: Academic Press.

Keenan, Edward L. \& Jonathan Stavi. 1986. A semantic characterization of natural language determiners. Linguistics and Philosophy 9(3). 253-326. http://dx.doi.org/10.1007/BFoo630273.

Kierstead, Gregory \& Scott Martin. 2012. A multistratal account of the projective Tagalog evidential 'daw'. In Semantics and Linguistic Theory (SALT) 22, 326-346. http://dx.doi.org/10.3765/salt.v22io.2653.

Koev, Todor. 2012. On the information status of appositive relative clauses. In Maria Aloni, Vadim Kimmelman, Floris Roelofsen, Galit W. Sassoon, Katrin Schulz \& Matthijs Westera (eds.), Logic, language and meaning (Lecture Notes in Computer Science 7218), 401-410. Berlin \& Heidelberg: Springer. http://dx.doi.org/10.1007/978-3-642-31482-7_41.

Koev, Todor. 2014. Two puzzles about appositives: Projection and perspective shift. In Urtzi Exteberria, Anamaria Fălăuş, Aritz Irurtzun \& Bryan Leferman (eds.), Sinn und Bedeutung 18, 217-234. University of the Basque Country. http://semanticsarchive.net/sub2013/SeparateArticles/Koev.pdf.

Kubota, Yusuke \& Wataru Uegaki. 2009. Continuation-based semantics for conventional implicatures: The case of Japanese benefactives. In Semantics and Linguistic Theory (SALT) 19, 306-323. http://dx.doi.org/10.3765/salt. v19io.2522.

Lewis, David. 1979. Scorekeeping in a language game. Journal of Philosophical Logic 8(1). 339-359. http://dx.doi.org/10.1007/BFoo258436.

Martin, Scott. 2013. The dynamics of sense and implicature. Columbus, $\mathrm{OH}$ : Ohio State University dissertation. http://semanticsarchive.net/Archive/ DNmMjllM/Martin-dissertation.pdf. 
Supplemental update

Martin, Scott. 2015. A unidimensional syntax-semantics interface for supplements. In Workshop on empirical advances in categorial grammar, 82-106. Barcelona: European Summer School in Logic, Language \& Information (ESSLLI) 27. http://www.u.tsukuba.ac.jp/ kubota.yusuke.fn/cg2015proceedings.pdf.

Martin, Scott \& Carl Pollard. 2012a. A higher-order theory of presupposition. Studia Logica 100(4). 727-751. http://dx.doi.org/10.1007/s11225-012-94276.

Martin, Scott \& Carl Pollard. 2012b. Hyperintensional dynamic semantics: Analyzing definiteness with enriched contexts. In Philippe de Groote \& Mark-Jan Nederhof (eds.), Formal grammar 15 and 16 (Lecture Notes in Computer Science 7395), 114-129. Dordrecht: Springer. http://dx.doi.org/ 10.1007/978-3-642-32024-8_8.

Martin, Scott \& Carl Pollard. 2014. A dynamic categorial grammar. In Glyn Morrill, Reinhard Muskens, Rainer Osswald \& Frank Richter (eds.), Formal grammar 19 (Lecture Notes in Computer Science 8612), 138-154. Dordrecht: Springer. http://dx.doi.org/10.1007/978-3-662-44121-3_9.

McCready, Eric Scott. 2010. Varieties of conventional implicature. Semantics and Pragmatics 3(8). 1-57. http://dx.doi.org/10.3765/sp.3.8.

Murray, Sarah E. 2014. Varieties of update. Semantics and Pragmatics 7(2). 1-53. http://dx.doi.org/10.3765/sp.7.2.

Muskens, Reinhard. 1994. Categorial grammar and discourse representation theory. In Computational linguistics (COLING) 15, 508-514. http://dx.doi. org/10.3115/991886.991974.

Muskens, Reinhard. 1996. Combining Montague semantics and discourse representation theory. Linguistics and Philosophy 19(2). 143-186. http: //dx.doi.org/10.1007/BFoo635836.

Nouwen, Rick. 2007. On appositives and dynamic binding. Research on Language and Computation 5(1). 87-102. http://dx.doi.org/10.1007/s11168oo6-9019-6.

Nouwen, Rick. 2014. A note on the projection of appositives. In Eric McCready, Katsuhiko Yabushita \& Kei Yoshimoto (eds.), Formal approaches to semantics and pragmatics: Japanese and beyond (Studies in Linguistics and Philosophy 95), 205-222. Dordrecht: Springer. http://dx.doi.org/10.1007/97894-017-8813-7_10.

Pereira, Fernando. 2013. Meaning in the Wild. Invited talk at the Conference on Empirical Methods in Natural Language Processing (EMNLP) 18. Seattle, WA. 
Plummer, Andrew \& Carl Pollard. 2012. Agnostic possible worlds semantics. In Logical Aspects of Computational Linguistics (LACL) 7 (Lecture Notes in Computer Science 7351), 201-212. Berlin \& Heidelberg: Springer. http: //dx.doi.org/10.1007/978-3-642-31262-5_14.

Pollard, Carl. 2008. Hyperintensions. Journal of Logic and Computation 18(2). 257-282. http://dx.doi.org/10.1093/logcom/exmoo3.

Pollard, Carl. 2015. Agnostic hyperintensional semantics. Synthese 192(3). 535-562. http://dx.doi.org/10.1007/s11229-013-0373-2.

Pollard, Carl \& E. Allyn Smith. 2011. An alternative explanation for presupposition projection variability. Talk at the Workshop on Projective Meaning. Ljubljana: European Summer School in Logic, Language and Information (ESSLLI) 23.

Potts, Christopher. 2005. The logic of conventional implicatures (Oxford Studies in Theoretical Linguistics 7). New York \& Oxford: Oxford University Press.

Roberts, Craige. 1989. Modal subordination and pronominal anaphora in discourse. Linguistics and Philosophy 12(6). 683-721. http://dx.doi.org/10. 1007/BFoo632602.

Roberts, Craige. 2003. Uniqueness in definite noun phrases. Linguistics and Philosophy 26(3). 287-350. http://dx.doi.org/10.1023/A:1024157132393.

Roberts, Craige. 2005. Pronouns as definites. In Marga Reimer \& Anne Bezuidenhout (eds.), Descriptions and beyond, 503-543. New York \& Oxford: Oxford University Press.

Roberts, Craige. 2012a. Information structure: Afterword. Semantics and Pragmatics 5(7). 1-19. http://dx.doi.org/10.3765/sp.5.7.

Roberts, Craige. 2012b. Information structure in discourse: Towards an integrated formal theory of pragmatics. Semantics and Pragmatics 5(6). Accompanying afterword in Roberts 2012a., 1-69. http://dx.doi.org/10. 3765/sp.5.6.

Rooth, Mats. 1987. Noun phrase interpretation in Montague grammar, file change semantics, and situation semantics. In Peter Gärdenfors (ed.), Generalized quantifiers (Studies in Linguistics and Philosophy 31), 237268. Dordrecht: Springer. http://dx.doi.org/10.1007/978-94-009-3381-1_9. van der Sandt, Rob A. 1992. Presupposition projection as anaphora resolution. Journal of Semantics 9(4). 333-377. http://dx.doi.org/10.1093/jos/9.4.333. Schlenker, Philippe. 2010. Supplements within a unidimensional semantics I: Scope. In Maria Aloni, Harald Bastiaanse, Tiktu de Jager \& Katrin Schulz (eds.), Logic, language and meaning (Lecture Notes in Computer Science 
Supplemental update

6042), 74-83. Dordrecht: Springer. http://dx.doi.org/10.1007/978-3-64214287-1_8.

Schlenker, Philippe. 2013a. Supplements within a unidimensional semantics II: Epistemic status and projection. In Seda Kan, Claire Moore-Cantwell \& Robert Staubs (eds.), Northeast Linguistic Society (NELS) 4O, vol. 2, 167-182. Amherst, MA: Graduate Linguistics Student Association.

Schlenker, Philippe. 2013b. Supplements without bidimensionalism. Unpublished manuscript, Institut Jean-Nicod and New York University. February, 2013. http:/ / www . semanticsarchive . net / Archive / jgwMjNmM / Supplements_without_Bidimensionalism.pdf.

Simons, Mandy, Craige Roberts, David Beaver \& Judith Tonhauser. 2010. What projects and why. In Semantics and Linguistic Theory (SALT) 20, 309-327. http://dx.doi.org/10.3765/salt.v20io.2584.

Stalnaker, Robert. 1978. Assertion. In Peter Cole (ed.), Pragmatics, vol. 9 (Syntax and Semantics), 315-332. New York: Academic Press.

Tonhauser, Judith, David Beaver, Craige Roberts \& Mandy Simons. 2013. Toward a taxonomy of projective content. Language 89(1). 66-109. http: //dx.doi.org/10.1353/lan.2013.0001.

Wang, Linton, Eric McCready \& Nicholas Asher. 2006. Information dependency in quantificational subordination. In Klaus von Heusinger \& Ken Turner (eds.), Where semantics meets pragmatics (Current Research in the Semantics/Pragmatics Interface 16), 267-306. Amsterdam: Elsevier. http://germanistischelinguistik.phil-fak.uni-koeln.de/kvh/pub/pubo5o6/Heusinger20o6_CRiSPI_SemPrag.pdf.

Wang, Linton, Brian Reese \& Eric McCready. 2005. The projection problem of nominal appositives. Snippets 10(1). 13-14. http://www.ledonline.it/ snippets/allegati/snippets10005.pdf.

Scott Martin

Natural Language Understanding

and Artificial Intelligence Laboratory

Nuance Communications, Inc.

1198 East Arques Avenue

Sunnyvale, California 94085 USA

http://coffeeblack.org/ 